\title{
Cerebrovascular amyloid Angiopathy in bioengineered vessels is reduced by high- density lipoprotein particles enriched in Apolipoprotein E
}

Jerome Robert ${ }^{1,2,3^{*}}$ (D) Emily B. Button ${ }^{1,2}$, Emma M. Martin ${ }^{1,2}$, Luke McAlary ${ }^{2,4}$, Zoe Gidden², Megan Gilmour ${ }^{1,2}$, Guilaine Boyce ${ }^{1,2}$, Tara M. Caffrey ${ }^{1,2}$, Andrew Agbay ${ }^{1,2}$, Amanda Clark,2, Judith M. Silverman 2,5,

Neil R. Cashman ${ }^{5}$ and Cheryl L. Wellington ${ }^{1,2,6,7}$

\begin{abstract}
Background: Several lines of evidence suggest that high-density lipoprotein $(H D L)$ reduces Alzheimer's disease $(A D)$ risk by decreasing vascular beta-amyloid $(A B)$ deposition and inflammation, however, the mechanisms by which HDL improve cerebrovascular functions relevant to AD remain poorly understood.

Methods: Here we use a human bioengineered model of cerebral amyloid angiopathy (CAA) to define several mechanisms by which $\mathrm{HDL}$ reduces $A \beta$ deposition within the vasculature and attenuates endothelial inflammation as measured by monocyte binding.
\end{abstract}

Results: We demonstrate that $\mathrm{HDL}$ reduces vascular $A \beta$ accumulation independently of its principal binding protein, scavenger receptor (SR)-BI, in contrast to the SR-BI-dependent mechanism by which HDL prevents A $\beta$ induced vascular inflammation. We describe multiple novel mechanisms by which HDL acts to reduce CAA, namely: i) altering $A \beta$ binding to collagen-I, ii) forming a complex with $A \beta$ that maintains its solubility, iii) lowering collagenI protein levels produced by smooth-muscle cells (SMC), and iv) attenuating $A \beta$ uptake into SMC that associates with reduced low density lipoprotein related protein 1 (LRP1) levels. Furthermore, we show that HDL particles enriched in apolipoprotein (apo)E appear to be the major drivers of these effects, providing new insights into the peripheral role of apoE in AD, in particular, the fraction of $\mathrm{HDL}$ that contains apoE.

Conclusion: The findings in this study identify new mechanisms by which circulating HDL, particularly HDL particles enriched in apoE, may provide vascular resilience to $A \beta$ and shed new light on a potential role of peripherally-acting apoE in AD.

Keywords: Alzheimer's disease, Cerebrovasculature, High-density lipoprotein (HDL), Cerebral amyloid angiopathy (CAA), Endothelial inflammation, Apolipoprotein (apo)E, Tissue engineering

\footnotetext{
* Correspondence: jrme.robert@gmail.com

'Department of Pathology and Laboratory Medicine, University of British

Columbia, Vancouver, British Columbia V6T 1Z3, Canada

${ }^{2}$ Djavad Mowafaghian Centre for Brain Health, University of British Columbia,

Vancouver, British Columbia V6T 1Z3, Canada

Full list of author information is available at the end of the article
}

(c) The Author(s). 2020 Open Access This article is distributed under the terms of the Creative Commons Attribution 4.0 International License (http://creativecommons.org/licenses/by/4.0/), which permits unrestricted use, distribution, and reproduction in any medium, provided you give appropriate credit to the original author(s) and the source, provide a link to the Creative Commons license, and indicate if changes were made. The Creative Commons Public Domain Dedication waiver (http://creativecommons.org/publicdomain/zero/1.0/) applies to the data made available in this article, unless otherwise stated. 


\section{Background}

As our population ages, the burden of cardiometabolic, neurodegenerative and neuroinflammatory diseases is growing rapidly. Alzheimer's Disease (AD) is defined by the presence of beta-amyloid $(A \beta)$ deposits and neurofibrillary tangles in the brain and affects over 50 million people worldwide with a global economic burden closed to one trillion US dollars [1]. Despite decades of research, there is not yet an approved disease-modifying therapy for $\mathrm{AD}$, as many drugs that target parenchymal pathologies have been ineffective in attenuating cognitive decline [2]. One exception may be the anti-amyloid immunotherapy aducanumab, which clears amyloid from the brain [3] and appears to slow cognitive decline at the highest dose so far tested [4]. However, amyloid related imaging abnormities (ARIA), including edema (ARIA-E) and microhemorrhage (ARIA-H) are adverse effects associated with anti-amyloid immunotherapies and these risks are elevated in elderly people with cerebrovascular disease [5]. Thus, novel preventative and therapeutic approaches are urgently needed, particularly with respect to the vascular contributions to AD.

The importance of the cerebrovasculature in $\mathrm{AD}$ is underscored by the observation that up to $90 \%$ of AD autopsy cases have evidence of cerebral small vessel disease, including vascular microbleeds, vascular degeneration and deposition of $A \beta$ in the vascular wall, a condition known as cerebral amyloid angiopathy (CAA) [6]. Sporadic CAA is also present in 10-40\% of elderly brains [7]. Cerebrovascular pathologies precede other pathophysiological conditions and are believed to exacerbate or even initiate AD and neuroinflammation [8], perhaps by reflecting an age-related decline in the ability to clear $A \beta$ from the brain by multiple pathways involving the cerebrovasculature [9]. Additionally, multiple cardiovascular risk factors such as hypertension, type II diabetes and dyslipidemia increase AD risk $[10,11]$ and a favourable cardiovascular health or management of cardiovascular risk factors, especially at midlife, may attenuate dementia risk decades later [12-14]. The clinical precedence of systemic factors that can affect AD pathogenesis raises the possibility that promoting vascular resilience may be an attractive preventative or therapeutic approach $[15,16]$.

High density lipoprotein (HDL) is a circulating lipid carrier that is best known for its pivotal role in reverse cholesterol transport, which is the process by which excess cholesterol is removed from cells and transported to the liver for excretion into bile [17]. HDL also has potent anti-thrombotic, anti-oxidant, anti-inflammatory and cytoprotective functions [18], all of which may affect AD. There is epidemiological evidence that AD risk can be attenuated by HDL levels [19]. Specifically, apolipoprotein (apo)A-I, the major HDL-associated protein, positively correlates with cognitive scores [20] and high serum HDL-cholesterol (> $55 \mathrm{mg} / \mathrm{dl}$ ) in cognitively normal elderly individuals associates with reduced AD risk (hazard ratio (HR) 0.4) after adjusting for $A P O E$ genotype and vascular risk factors [21]. In mouse models of amyloidogenesis, deficiency of apoA-I, which leads to low HDL levels, is reported to selectively exacerbate CAA and cerebrovascular inflammation $[22,23]$, although other groups recently reported either no effect [24] or the opposite result [25]. Conversely, genetic apoA-I overexpression reduces CAA and neuroinflammation [26], and delivery of recombinant HDL or apoA-I Milano into the systemic circulation acutely decreases soluble brain $A \beta$ levels and leads to longlasting lowering of CAA and neuroinflammation, respectively $[27,28]$. Importantly, although lipoprotein composition is generally similar between mice and humans [29], circulating lipids are mainly carried by HDL in rodents whereas they are mainly carried on low density lipoproteins (LDL) in humans, which may limit the translational relevance of some animal model studies [30].

We previously described a new human in vitro model of three-dimensional (3D) perfusable bioengineered vessels to study $\mathrm{CAA}$ and $\mathrm{A} \beta$-associated vascular inflammation $[31,32]$. In this study we use this vascular model to define several mechanisms by which HDL reduces $A \beta$ accumulation in the engineered vascular wall and attenuates $A \beta$ induced vascular inflammation. First, the anti-CAA and anti-inflammatory functions of HDL are mediated by distinct mechanisms. HDL prevents $A \beta$ vascular accumulation independently of its primary receptor, scavenger receptor (SR)-BI, in contrast to the previously described SR-BI-dependent mechanism by which HDL prevents A $\beta$ induced monocyte binding [32]. Second, delving deeper into HDL's anti-CAA functions, we define four distinct pathways that HDL uses to attenuate $A \beta$ accumulation, namely: i) altering $A \beta$ binding to collagen-I, ii) forming a complex with $A \beta$ that maintains its solubility, iii) diminishing collagen-I protein levels produced by smooth muscle cells (SMC), and iv) attenuating $\mathrm{A} \beta$ uptake into SMC that is associated with reduced low density lipoprotein receptor-related protein (LRP) 1 levels. We also define a specific subfraction of HDL that may be particularly relevant to $\mathrm{AD}$. Although only $\sim 6 \%$ of circulating $\mathrm{HDL}$ lipoprotein particles contain apoE [33], it is this fraction of apoE-containing HDL (HDL-apoE) that appears to have the most potent effects on vascular amyloid deposition. ApoE is a major genetic risk factor for sporadic $A D$, where, in the brain, apoE is produced by astrocytes, microglia, pericytes and stressed neurons and contributes to $\mathrm{AD}$ pathogenesis by modulating multiple pathways, including but not limited to $\mathrm{A} \beta$ metabolism, tauopathy, and neuroinflammation [34]. Our observations provide new evidence that peripheral apoE, particularly the apoE found on a small fraction of circulating HDL lipoprotein particles, may play a greater role in $\mathrm{AD}$ pathogenesis than previously recognized. 


\section{Methods}

\section{Cells, lipoproteins and bioengineered tissues}

Experiments with human cells were conducted under an approved clinical protocol (UBC Clinical Ethics Research Board H13-02719) after obtaining written informed consent. Human umbilical vein endothelial cells (EC) and human umbilical vein myofibroblasts (SMC) were isolated as described [31]. Briefly, EC were isolated using the collagenase $(2 \mathrm{mg} / \mathrm{ml}$, Collagenase A, Roche) instillation method and expanded in complete endothelial growth medium (EGM ${ }^{\mathrm{ms}}$-2) (LONZA Inc., supplemented with vascular endothelial growth factor (VEGF), human recombinant insulin-like growth factor-1 (hrIGF-1), human epidermal growth factor (hEGF), amphotericin-B, hydrocortisone, ascorbic acid, heparin, and $2 \%$ foetal bovine serum (FBS)) up to passage 8. SMCs were isolated by mincing the umbilical vein into small pieces $(\sim 2-3$ $\mathrm{mm}$ ) and expended in Advanced DMEM (Gibco) supplemented with 1\% L-glutamine (Gibco), 0.05\% Pen/Strep (Gibco) and 10\% heat inactivated FBS (Gibco) up to passage 10. The RAW 264.7 murine macrophage line was purchased from ATCC and grown in DMEM (Gibco) containing 10\% heat inactivated FBS, 1\% L-glutamine and $0.05 \%$ Pen/Strep. Human primary astrocytes (Sciencell) were grown in complete astrocyte media containing 2\% FBS (Sciencell) up to passage 6. Experiments with human blood were conducted under an approved clinical protocol (UBC Clinical Ethics Research Board H1403357) and upon receipt of written informed consent. HDL (density $1.063-1.21 \mathrm{~g} / \mathrm{mL}$ ) and a mixture of plasma lipoprotein classes (very low density lipoprotein; vLDL, intermediate density lipoprotein; IDL and low density lipoprotein; LDL) (density $<1.063 \mathrm{~g} / \mathrm{mL}$ ) were isolated by $\mathrm{KBr}$ gradient ultra-centrifugation from blood of healthy volunteers and tested by SDS-PAGE as described [35] or purchased (Lee Biosource). Depletion or enrichment of apoE in HDL was performed as described [36]. Briefly, HDL was loaded on an apoE immunoaffinity column (Academy Biomedical) and incubated overnight at $4{ }^{\circ} \mathrm{C}$ before collecting the unbound fraction (apoE-depleted HDL). The column was then washed four times with PBS before eluting the bound fraction of HDL enriched in apoE (HDL-apoE) using $3 \mathrm{M} \mathrm{NaSCN}$. Collected fractions were then extensively dialyzed against $400 \mathrm{mM}$ $\mathrm{NaCl}$ and $1 \mathrm{mM}$ EDTA.

HDL was fluorescently labeled using Alexa-647 (Invitrogen) or Atto-594 (Sigma Aldrich) following the manufacture's guidelines and stored for a maximum of 1 month at $4{ }^{\circ} \mathrm{C}$ until use. Frozen brain tissues (cortex Brodmann area 9) from AD patients (Braak stage 4) or cognitively normal controls were provided by the Harvard Brain Tissue Resource Center under the approved UBC protocol (C04-0595) and maintained at $-80^{\circ} \mathrm{C}$ until processing.

\section{Fabrication of engineered vessels}

Bioengineered vessels were fabricated using a dynamic, semi-pulsatile flow bioreactor system as described, illustrated in Sup. Fig. 1 [31, 32]. Briefly, tubular biodegradable scaffolds (length $1.5 \mathrm{~cm}$ and inner diameter $2 \mathrm{~mm}$ ) were produced from non-woven polyglycolic acid (PGA, Biomedical Structure) meshes (thickness: $1 \mathrm{~mm}$ and density: $70 \mathrm{mg} / \mathrm{cc})$ dip-coated with a $1.75 \%(\mathrm{w} / \mathrm{w})$ polycaprolactone (PCL) (80 kDa, Sigma Aldrich)/tetrahydrofuran (THF, Sigma Aldrich) solution and externally coated with a $10 \%$ $\mathrm{PCL} / \mathrm{THF}(\mathrm{w} / \mathrm{w})$ solution. For bipartite vessels that resemble leptomeningeal arteries, ethanol-sterilized scaffolds were seeded with SMCs $\left(2-3 \times 10^{6}\right.$ cells $/ \mathrm{cm}^{2)}$ on the inner surface of the scaffold using fibrin gel (fibrinogen $10 \mathrm{mg}$ clottable protein/ml PBS and thrombin 100-10 mU/ml PBS) as a cell carrier. After 3-4 days under static conditions, vascular tissues were exposed to dynamic flow. The flow of nutrient medium (AdvDMEM supplemented with 10\% FBS, 1\% Lglutamine, $0.05 \%$ Pen/Strep and $1.5 \mathrm{mML}$-ascorbic acid (Sigma Aldrich)) was directed through the lumen of the vascular tissue to mimic blood flow for 7 days. HUVEC (1$1.5 \times 10^{6}$ cells $/ \mathrm{cm}^{2}$ ) were then seeded on the inner surface of the lumen and tissues were maintained first in static conditions for 5 days in $\mathrm{EGM}^{\mathrm{Tx}}-2$ supplemented as above but with $10 \%$ FBS. After the static phase, vascular tissues were placed back in the bioreactor for 10 additional days. For tripartite tissues that resemble cortical penetrating arteries, astrocytes $\left(1 \times 10^{6}\right.$ cells $\left./ \mathrm{cm}^{2}\right)$ were seeded on the antelumen of the vessel surface using fibrin as cell carrier 4-5 days after seeding EC and directly placed under flow condition for 10 days with complete astrocyte media in the tissue chamber and $\mathrm{EGM}^{\mathrm{Tm}}-2$ supplemented as above with $10 \%$ FBS perfused through the lumen for 10 days. The vascular structure was evaluated by immunofluorescence and assessing the integrity of the endothelium using Evans blue as described [37] (Figs. 1a, b and 5a).

\section{Preparation of $A \beta$ peptides}

Recombinant A $\beta 42$ (California Peptide, USA) or FITCA 342 peptides (BACHEM, Switzerland) were dissolved in hexafluoroisopropanol (HFIP) to a concentration of 1 $\mathrm{mM}$ as described [32]. HFIP was removed by evaporation overnight and dried stocks were stored at $-20^{\circ} \mathrm{C}$. On the day of the assay, soluble monomers were prepared by reconstituting the peptide film in DMSO to 5 $\mathrm{mM}$, which was diluted further to $100 \mu \mathrm{M}$ in RPMI containing $1 \%$ Pen/Strep but without FBS. $100 \mu \mathrm{l}$ of $\mathrm{A} \beta$ solution was injected into the tissue chamber containing $900 \mu \mathrm{l}$ of complete astrocyte media (Sciencell) to the desired concentration using a syringe. For A $\beta 42$ oligomers and fibrils, after reconstitution in RPMI, A $\beta 42$ was incubated at either $4{ }^{\circ} \mathrm{C}$ (oligomers) or $37^{\circ} \mathrm{C}$ (fibrils) for $48 \mathrm{~h}$ before injection into the tissue chamber. 

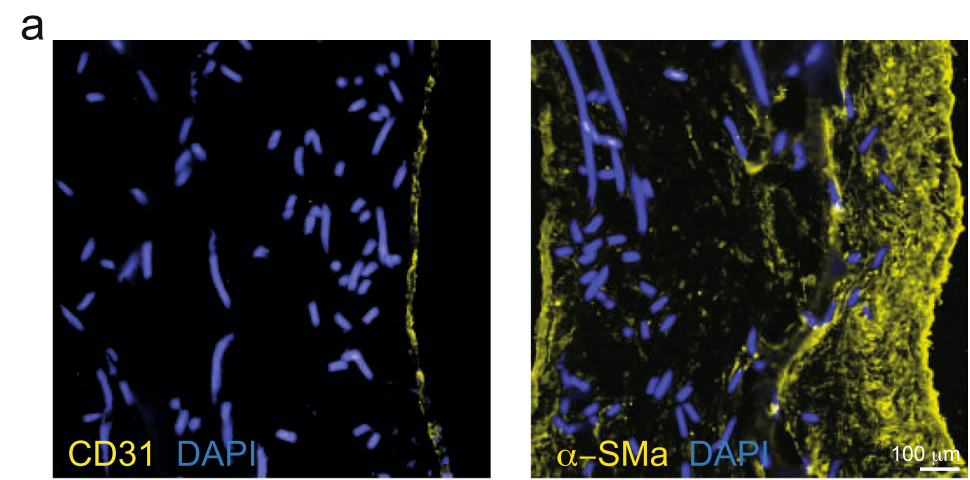

b

Evan's blue

C

media
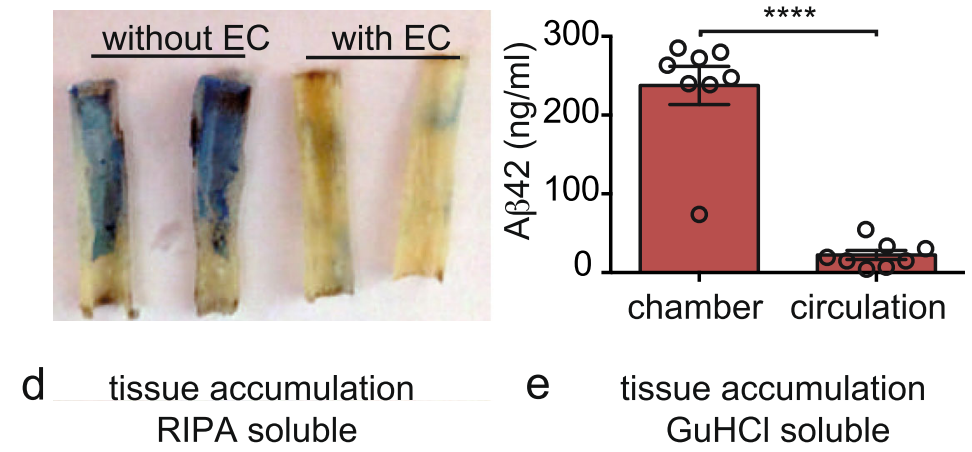

e tissue accumulation

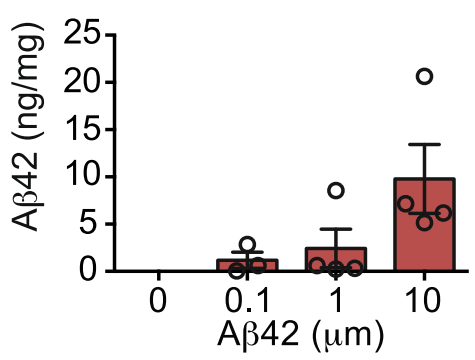

$\mathrm{GuHCl}$ soluble
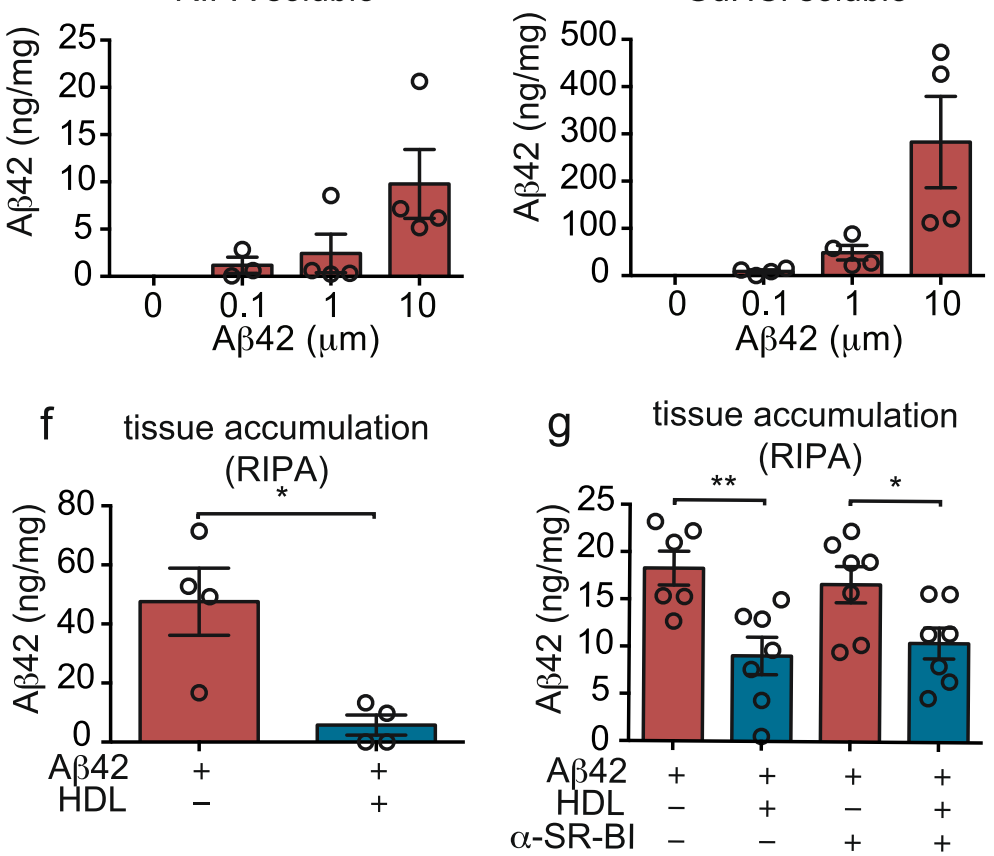

Fig. 1 Human in vitro bioengineered vessels model CAA. a Immunofluorescent staining for CD31 confirms the formation of an endothelial monolayer surrounded by several layers of SMC stained for a-SM actin. $\mathbf{b}$ Evans blue staining confirms a tight endothelial barrier 10 days after endothelialisation. In (a) and (b), autofluorescence of the scaffold material is visible in the DAPI channel. c After injecting $1 \mu \mathrm{M}$ of A 42 in the antelumen (tissue chamber), tissue chamber and circulation media were collected and A 342 was quantified by ELISA. d-e $24 \mathrm{~h}$ after injection of the indicated A 342 concentration into the tissue chamber, tissues were lysed in RIPA buffer before solubilizing the pellet in GuHCl followed by Aß42 quantification using ELISA. f After injecting $1 \mu \mathrm{M}$ of $A \beta 42$ in the tissue chamber, $200 \mu \mathrm{g} / \mathrm{mL}$ of $\mathrm{HDL}$ was circulated through the lumen. After $24 \mathrm{~h}, \mathrm{~A} \beta 42$ accumulation was measured as above. $\mathbf{g}$ A blocking antibody against the HDL binding protein SR-BI was circulated in the presence of $200 \mu \mathrm{g} / \mathrm{mL}$ of HDL or BSA through the lumen after injecting Aß42 into the tissue chamber. A 42 accumulation was measured as above. Points in graphed data represent individual bioengineered vessels, bars represent mean, error bars represent \pm SEM and analysed by Student' t-test or one way ANOVA ${ }^{*} P<0.05,{ }^{* *} P<0.01,{ }^{* * *} P<0.001$ and ${ }^{* * * *} P<0.0001$ 


\section{$A \beta 42$ accumulation in bioengineered vessels}

After 10 days under flow conditions after endothelization, the indicated concentration of monomers, oligomers or fibrils $A \beta 42$ was injected into the tissue chamber (antelumen) in the absence or presence of $200 \mu \mathrm{g}$ of protein $/ \mathrm{mL}$ of HDL, LDL or BSA (vehicle control) that was injected into the bioreactor circulation loop (Sup. Fig. 1). Tissues were maintained under flow conditions during the entire experiment. At the indicated times, $5 \mathrm{~mm}$ tissue rings were collected, mechanically crushed and lysed in RIPA buffer (10 $\mathrm{mM}$ Tris $\mathrm{pH} 7.4,150 \mathrm{mM} \mathrm{NaCl}, 1.0 \% \mathrm{NP}-40,1.0 \%$ sodium deoxycholate, $0.1 \%$ SDS and cOmplete protease inhibitor with EDTA (Roche)). After homogenization, samples were centrifuged for $15 \mathrm{~min}$ at $14000 \mathrm{~g}$ at $4{ }^{\circ} \mathrm{C}$ and the RIPA soluble fraction was transferred to a new tube. $5 \mathrm{mM}$ of guanidine (GuHCl, Sigma Aldrich) was added to the tissue pellet and incubated at room temperature overnight under constant agitation before centrifugation at $14000 \mathrm{~g}$ at $4{ }^{\circ} \mathrm{C}$ for $15 \mathrm{~min}$. RIPA soluble and $\mathrm{GuHCl}$ soluble fractions were stored at $-20^{\circ} \mathrm{C}$ until quantification. RIPA (soluble) and $\mathrm{GuHCl}$ (insoluble) fractions were diluted 10 and 20 times respectively to quantify $\mathrm{A} \beta 42$ using a commercial ELISA kit (KHB3482, Life Tech) and normalized to total protein concentration measured by BCA assay (Fisher). Media collected in the tissue or circulating chambers $24 \mathrm{~h}$ after A $\beta 42$ injection was diluted 100 times with complete EGM2 and $A \beta 42$ levels were quantified as above.

\section{Tissue inhibitor experiments}

After ten days under flow conditions after endothelization, the indicated concentration of $1 \mu \mathrm{M}$ A $\beta 42$ was injected into the tissue chamber (antelumen) in the absence or presence of antibodies against SR-BI (NB400-113 Novus, 1:500, RRID:AB_1291690), or RAGE (MAB11451, R\&D Systems, 1:50 RRID:AB_2224344), or recombinant receptor associated protein (RAP, Oxford biome $1 \mu \mathrm{M}$ ) that was injected into the bioreactor circulation loop. Tissues were then analyzed as described above for $\mathrm{A} \beta 42$ accumulation or monocyte binding.

\section{FITC-A $\beta 42$ binding to collagen-I}

Black 96-well plates were coated with a solution of rat-tail collagen-I (Fischer) or with $10 \%$ BSA in PBS at $37^{\circ} \mathrm{C}$. After $16 \mathrm{~h}$, wells were washed three times with PBS before adding $100 \mu \mathrm{l}$ of FITC-A $342(1 \mu \mathrm{M})$ in RPMI media with $200 \mathrm{mg} / \mathrm{ml}$ of HDL or BSA and placed back in humidified incubator at $37^{\circ} \mathrm{C}$ and $5 \% \mathrm{CO}_{2}$ for $24 \mathrm{~h}$. Wells were then washed three times with PBS before excitation at $490 \mathrm{~nm}$ and measuring emission intensity at $520 \mathrm{~nm}$ using an Infinite M2000 Pro plate reader (Tecan).

\section{Histology and immunofluorescence}

Bioengineered vessels were fixed in $4 \%$ paraformaldehyde (PFA) for $30 \mathrm{~min}$, cryopreserved in $20 \%$ sucrose in
PBS for a minimum of $1 \mathrm{~h}$, embedded in $5 \%$ bovine skin gelatin (Sigma Aldrich) and 20\% sucrose in PBS and stored at $-80{ }^{\circ} \mathrm{C}$ until processed. Human cortical samples were stored at $-80^{\circ} \mathrm{C}$ until processed. On the processing day, samples were mounted in optimal cutting temperature (OCT) matrix before being sectioned on a cryotome (Leica). Briefly, bioengineered vessels and human cortical tissues were sectioned at $20 \mu \mathrm{m}$, with object and chamber temperatures of $-30{ }^{\circ} \mathrm{C}$ (engineered tissues) or $-20^{\circ} \mathrm{C}$ (cortex), and sections were stored at $80^{\circ} \mathrm{C}$ until staining. For staining, sections were placed at room temperature for $10 \mathrm{~min}$ and rehydrated in PBS for 10 min. Human brain sections were then fixed for 15 min at room temperature followed by one $0.5 \mathrm{M}$ trisHCL (pH 8) and two PBS washes. SMC in 2D culture were grown on sterile microscope cover glasses (Paul Marlenfeld $\mathrm{GmbH} \& \mathrm{Co}$ ) in 24 well plates or chamber slides (Fisher). After the indicated culture time, cells were washed three times with PBS, fixed with $4 \%$ PFA and washed once with $0.5 \mathrm{M}$ Tris-HCL $(\mathrm{pH} 8)$ and twice with PBS.

Tissue sections and SMC cultured on coverslips were stained for endothelial markers CD31 (Biolegend, WM59, RRID: AB_31432) and vWF (Sigma Aldrich, AB_259543), muscular marker $\alpha$-SM actin (Sigma Aldrich, 1A4, RRID: AB_476856), astrocyte marker GFAP (Abcam, GA5, RRID: AB_880203), amyloid marker A $\beta$ 1-16 (Biolegend, 6E10, RRID_AB2533200), extracellular matrix markers collagen-I (Abcam, RRID: AB_731684), collagen-IV (EMD Millipore, RRID:AB_ 2276457), laminin (Abcam, RRID:AB_476856), biglycan (Abcam, RRID: AB_1523212), versican (Abcam, RRID: AB444865) and heparan sulfate proteoglycan (Abcam, A76L, RRID: AB_2295402), lysosome LAMP1 (Abcam, RRID: AB_775978) or Wheat Germ Agglutinin (WGA, ThermoFisher) as described [31]. Briefly, after rehydration in PBS for sections and fixation for SMC, samples were blocked at room temperature in PBS containing 5\% donkey serum and 1\% BSA (Sigma Aldrich). After $30 \mathrm{~min}$ samples were incubated overnight at $4{ }^{\circ} \mathrm{C}$ in a humidified chamber with specific antibodies against CD31 (1:50), von Willebrand factor (1:200), $\alpha$-SM-actin (1:200), GFAP (1:200), 6E10 (1: $100)$, collagen-I (1:200), collagen-IV (1:200), laminin (1:200), versican (1:200), biglycan (1:200), heparan sulphate proteoglycan (1:200) and LAMP1 (1:100). After three additional PBS washes, samples were incubated for $60 \mathrm{~min}$ at RT with donkey anti-rabbit or donkey anti-mouse Alexa-488 or Alex-594 secondary antibodies (Invitrogen, 1:600). After three additional PBS washes, sections were mounted in Prolong Gold antifade containing DAPI (ThermoFisher Scientific) and imaged using an Axioscan inverted microscope or Axioscan inverted confocal microscope (Zeiss). 


\section{SDS-PAGE, native-PAGE and Immunoblotting}

SMC or whole tissues were lysed in RIPA buffer (defined above) and centrifuged for $10 \mathrm{~min}$ at $12,000 \mathrm{~g}$ at $4{ }^{\circ} \mathrm{C}$. Total protein concentrations were quantified using a BCA assay. Equal amounts of total protein $(25 \mu \mathrm{g})$ were separated by either SDS-PAGE or Native PAGE, followed by electrophoretic transfer to polyvinylidene fluoride (PVDF) membranes (Millipore). Membranes were blocked for $1 \mathrm{~h}$ using 5\% skim milk powder in PBS containing $0.5 \%$ Triton X (PBST). Collagen-I (Abcam, RRID: AB_731684, 1:1000), ApoE (Cell Signaling, D7I9N, RRID:AB_2798191, 1:1000), ApoA-I (Brookwood Biomedical, RRID: AB_2801381, 1:2000), ApoA-II (Abcam, RRID: $\left.\mathrm{AB} \_447950,1: 5000\right), \mathrm{A} \beta$ 1-16 (Biolegend, 6E10, RRID_ AB2533200, 1:1000), LRP1 (Abcam, EPR3724, RRID: AB 2234877, 1:20000), RAGE (Abcam, RRID: AB_2242462, 1: 1000), GAPDH (EMD Millipore, RRID:AB_2107445, 1: 1000) and Actin (Abcam, ACTN05 (C4), RRID: AB $303668,1: 1000)$ were immunodetected by incubating in primary antibody for $16 \mathrm{~h}$ in blocking buffer at $4{ }^{\circ} \mathrm{C}$. Membranes were washed extensively with PBST and incubated with anti-mouse, anti-goat or anti-rabbit (1:1000-10,000, Jackson ImmunoResearch) secondary antibody in blocking buffer. After $1 \mathrm{~h}$, membranes were washed extensively with PBST, developed using enhanced chemiluminescence (ECL, Amersham) and imaged using ChemiDoc MP imager (Biorad). Band densitometry was quantified using image J and normalized to loading control, actin or GAPDH.

\section{Flow cytometry}

SMC and EC were seeded in 6-well plates at a concentration of 300,000 and 500,000 cells per well, respectively. After two days in culture, cells were incubated with $0.1 \mu \mathrm{M}$ of FITC-A $\beta 42$ (Bachem) in the absence or presence of $200 \mu \mathrm{g} / \mathrm{mL}$ of $\mathrm{HDL}$ or $\mathrm{BSA}$ in respective growth media. After 3 or $24 \mathrm{~h}$, cells were washed twice with $\mathrm{PBS}$, detached using $0.25 \%$ trypsin for $5 \mathrm{~min}$ at $37^{\circ} \mathrm{C}$ before adding RPMI to collect the cells. Floating cells were pelleted by centrifugation $(300 \mathrm{~g})$ for $5 \mathrm{~min}$, washed four times with FACS buffer (PBS containing 2\% FBS, $1 \mathrm{mM}$ EDTA and $0.1 \%$ sodium azide), and suspended in a final volume of $200 \mu \mathrm{L}$ of FACS buffer and counted immediately using a $\mathrm{BD}^{\mathrm{TM}}$ LSRII flow cytometer. Data were analysed using FlowJo software (RRID:SCR_ 008520).

\section{Gel-filtration chromatography}

A Superdex 200-increase 10/300 column was equilibrated in filtered and degassed phenol red-free DMEM and $0.02 \%$ sodium azide overnight prior to loading of protein samples. HFIP treated A $\beta 42$ was reconstituted in $100 \%$ DMSO prior to dilution in DMEM to a concentration of $100 \mu \mathrm{M}$ or mixing with $1 \mathrm{mg} / \mathrm{mL}$ HDL or BSA. The sample was then centrifuged at $20,000 \times \mathrm{g}$ for 10 min before $100 \mu \mathrm{L}$ of supernatant was injected onto the column and run at a flow rate of $0.4 \mathrm{~mL} / \mathrm{min}$. Following sample injection, $0.5 \mathrm{~mL}$ fractions were collected across the entire column volume of each run. Collected fractions were stored at $-20{ }^{\circ} \mathrm{C}$ prior to being processed by dot blot. Protein standards were run under the same conditions as above, and included alcohol dehydrogenase $(150 \mathrm{kDa})$, BSA $(66 \mathrm{kDa})$, carbonic anhydrase $(29 \mathrm{kDa})$, and cytochrome c $(12.4 \mathrm{kDa})$, all purchased from Sigma Aldrich. Gel-filtration fractions, collected as column eluents, were loaded onto nitrocellulose membranes through a round slot-format 96-well microfiltration apparatus (Biorad), then immunodetected and developed following the above immunoblotting protocol. Densitometry was performed with Image Lab (Biorad, RRID:SCR_001935).

\section{Cholesterol efflux}

RAW 264.7 cells were seeded at 150,000 cells/well in 24well plates and cultured for $24 \mathrm{~h}$ before labeling with $1 \mu \mathrm{Ci} / \mathrm{mL}$ of ${ }^{3} \mathrm{H}$-Cholesterol (PerkinElmer Life Sciences) in DMEM containing 10\% heat inactivated FBS, 1\% Pen/ Strep and 1\% L-glutamine. After $24 \mathrm{~h}$, labeled cells were washed and equilibrated in serum-free media for at least $60 \mathrm{~min}$. Serum-free media was then added to the cells in the absence (NA, no acceptor) or presence of $50 \mu \mathrm{g} / \mathrm{mL}$ of HDL or $10 \mu \mathrm{g} / \mathrm{mL}$ of exogenous human serum delipidated apoA-I (a gift from CSL Behring, Switzerland) that was previously incubated for $24 \mathrm{~h}$ with $1 \mu \mathrm{M} \mathrm{A} \beta 42$ or DMSO at $4{ }^{\circ} \mathrm{C}$. After $4 \mathrm{~h}$ at $37^{\circ} \mathrm{C}$, culture media was collected and cells were lysed with $0.1 \mathrm{M} \mathrm{NaOH}$ with $0.2 \%$ SDS, followed by incubation at room temperature for a minimum of $1 \mathrm{~h}$. $\beta$-radiation in media and cell lysate samples were quantified by scintillation counting (PerkinElmer). The percentage cholesterol efflux was calculated as the total counts per minute (CPM) in the media divided by the sum of the CPM in the media plus in the cell lysate [38].

\section{Thioflavin-T quantification}

Cell-free Thioflavin- $T$ fibrillization assays were performed as described [32]. Briefly, $10 \mu \mathrm{M}$ monomeric A 342 were incubated in $20 \mathrm{mM}$ of Thioflavin- $\mathrm{T}$ in 150 $\mathrm{mM} \mathrm{NaCl}$ and $5 \mu \mathrm{M}$ of HEPES at $\mathrm{pH} 7.4$, with and without $1 \mathrm{mg} / \mathrm{mL}$ of $\mathrm{HDL}, \mathrm{LDL}$ or BSA, at $37^{\circ} \mathrm{C}$ with $20 \mathrm{~s}$ of orbital shaking ( $3 \mathrm{~mm}$ amplitude) every $5 \mathrm{~min}$ in a black 96-well plate. Formation of fibrillar $\beta$-amyloid beta sheets over time was monitored by excitation at $440 \mathrm{~nm}$ and measuring emission intensity at $490 \mathrm{~nm}$ every $5 \mathrm{~min}$ up to $12 \mathrm{~h}$ in total using an Infinite M2000 Pro plate reader. Fibrillization curve were plotted using GraphPad Prism-5 software (RRID:SCR_002798), V50, final fluorescence and lag phase were measured as described [39]. 


\section{Statistics}

Comparisons between groups were performed using Student T-test when comparing two groups or one-way ANOVA with Dunnett or Bonferroni post hoc tests when comparing multiple groups. Data were obtained from at least 3 independently generated bioengineered vessels or experiments and graphically represented as mean \pm standard error of the mean (SEM). P-values of $<0.05$ were considered statistically significant. All statistical analyses were performed using GraphPad Prism-5 software (RRID:SCR_002798) or SPSS (RRID:SCR_002865).

\section{Results}

\section{Circulating HDL reduces vascular $A \beta 42$ accumulation independently of SR-BI in a human in vitro vascular model of CAA}

$\mathrm{CAA}$ is the accumulation of $\mathrm{A} \beta$ within leptomeningeal and cortical cerebral vessel walls. Although CAA is highly associated with the Flemish, Iowa and Dutch genetic mutations in amyloid precursor protein, sporadic CAA is present in $10-40 \%$ of non-cognitively declined elderly brains and in $80 \%$ of AD brains [7, 40]. To reproduce CAA in vitro, leptomeningeal-like vessels were fabricated by sequentially seeding primary human SMC and endothelial cells (EC) into a tubular scaffold. After 4 weeks under flow culture, immunohistochemical staining confirmed multiple layers of $\alpha$-smooth muscle actin $(\alpha-S M A)$ positive cells on the inner side of the scaffold and a monolayer of CD31 positive EC lining the vascular lumen (Fig. 1a). Integrity of the endothelial barrier was demonstrated by injecting Evans blue into the circulation loop of the bioreactor and observing exclusion from engineered tissues after endothelization (Fig. 1b). CAA is modeled by injecting monomeric $A \beta$ into the tissue chamber (antelumen; "brain side") of the bioreactor at the indicated final concentrations to mimic $A \beta$ produced by neurons that would be located around vessels (Sup. Fig. 1). Although $A \beta 40$ is the predominant $A \beta$ species in CAA, in this study we focused on $A \beta 42$ because it is considered indispensable to initiate CAA lesions [41] and because we previously reported that $\mathrm{HDL}$ has a stronger protective effect against $\mathrm{A} \beta 42$ vascular deposition compared to $A \beta 40$ [31]. Upon injection of $A \beta 42$ in the antelumen chamber, we confirmed endothelial barrier integrity by measuring $A \beta$ concentration by ELISA in both the antelumen chamber and in the circulating media $24 \mathrm{~h}$ after injection, and observed that $A \beta 42$ levels in the antelumen chamber remained 11 -fold more concentrated than in the circulation media (Fig. 1c). We also prepared RIPA and $\mathrm{GuHCl}$ fractions from tissues harvested 24 $\mathrm{h}$ after $\mathrm{A} \beta 42$ injection and, using ELISA, observed dose-dependent tissue accumulation of soluble and aggregated A 342 , respectively (Fig. 1d-e).
Multiple epidemiological studies associate high levels of plasma HDL at midlife with reduced $\mathrm{AD}$ risk, and several laboratories, including ours, demonstrated that HDL reduces CAA and vascular inflammation using in vitro and $A D$ rodent models [15, 27, 28, 31, 32]. However, the mechanisms by which HDL attenuates $\mathrm{A} \beta$-induced inflammation and reduces CAA remain unknown. As lipoprotein metabolism differs substantially between mice and humans [30], we used our engineered human CAA model to provide mechanistic insights as to how human HDL affects CAA in human bioengineered vessels. We first used A $\beta 42$ ELISA assays to confirm that circulating HDL $(200 \mu \mathrm{g} / \mathrm{mL})$ in the lumen reduced A $\beta 42$-vascular accumulation by 8 -fold in bioengineered vessels (Fig. 1f). Because SR$\mathrm{BI}$ is the principal binding partner of HDL on EC [42] and we previously showed that blocking SR-BI annihilates HDL ability to reduce $A \beta$-induced monocyte binding to EC [32], we tested whether blocking SR-BI using a specific antibody eliminated HDL's beneficial effects on $A \beta$ accumulation in the vascular wall. However, blocking SR-BI did not alter HDL's ability to reduce A $\beta 42$ accumulation by HDL, showing that HDL's anti-CAA activity is independent of SR-BI (Fig. 1g). Thus, the antiCAA and anti-inflammatory effects of HDL against $A \beta$ bifurcate along two major pathways; a SR-BI-independent pathway for CAA and a SR-BI-dependent pathway for A $\beta$ mediated endothelial inflammation.

\section{Reducing vascular $A \beta 42$ accumulation is specific to $\mathrm{HDL}$}

Previous studies have reported that HDL and associated apolipoproteins can alter $A \beta$ aggregation in vitro [32, 43, 44 , and here we show that a preparation consisting of low density lipoprotein (LDL), intermediate density lipoprotein (IDL) and very low density lipoprotein (VLDL) (density $<1.063 \mathrm{~g} / \mathrm{mL}$, mixLDL) also delays A 342 fibrillization using a cell-free Thioflavin- $\mathrm{T}$ fibrillization assay (Sup. Fig. 2a-d). We therefore tested if all of these plasma lipoproteins can reduce A $\beta 42$ accumulation in bioengineered vessels through which $200 \mu \mathrm{g} / \mathrm{mL}$ (total protein) of either HDL (density: $1.063-1.21 \mathrm{~g} / \mathrm{mL}$ ) or the mixLDL fraction, isolated from the same healthy normolipidemic individuals, was circulated. As HDL reduced A 342 accumulation by 2 -fold whereas mixLDL had no significant effect on tissue A $\beta 42$ levels measured $24 \mathrm{~h}$ after injection, only $\mathrm{HDL}$ can protect from vascular $\mathrm{A} \beta$ accumulation (Fig. 2a). We confirmed that HDL did not reduce RIPA-soluble $A \beta 42$ by shifting aggregates to the GluHCl-soluble fraction (Sup. Fig. 3a). HDL appears to act only on $A \beta$ monomers, as it failed to reduce $A \beta 42$ vascular accumulation after injecting either preformed oligomers or fibrils (Sup. Fig. $3 \mathrm{~b}-\mathrm{c}$ ), and does not reduce A $\beta 42$ accumulation when $A \beta 42$ is injected prior to HDL treatment (Sup. Fig. 3d). As HDL had no effect on A 342 
a tissue accumulation $24 \mathrm{~h} \mathrm{~b}$ (RIPA)

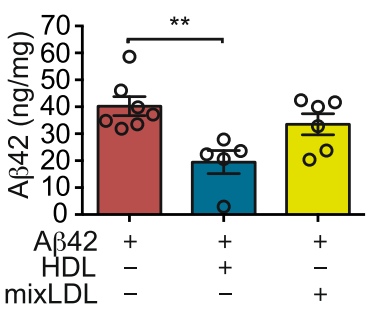

d

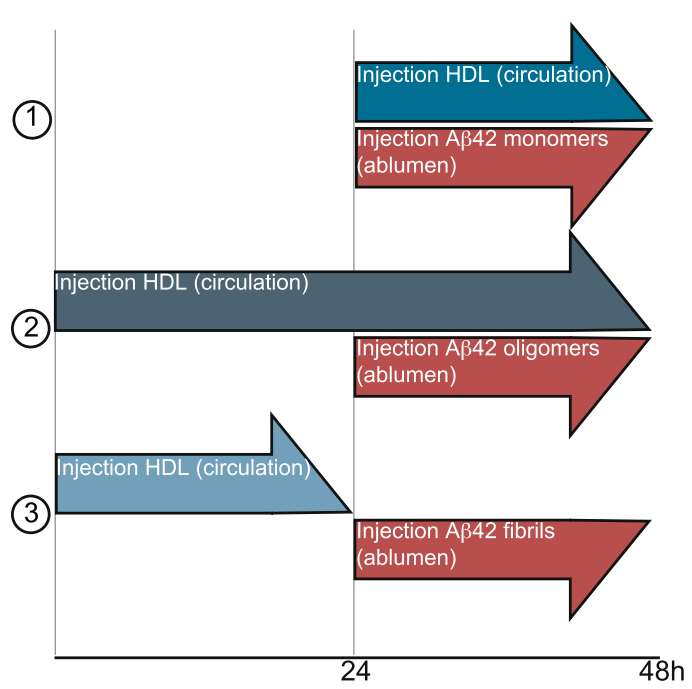

(RIPA)
C tissue accumulation $72 \mathrm{~h}$
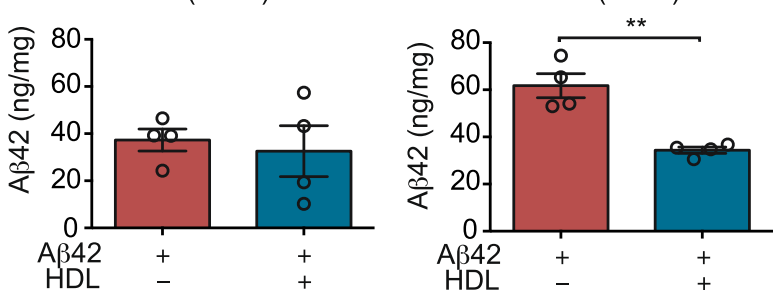

e tissue accumulation

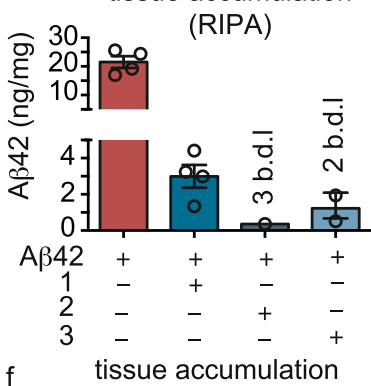

tissue accumulation

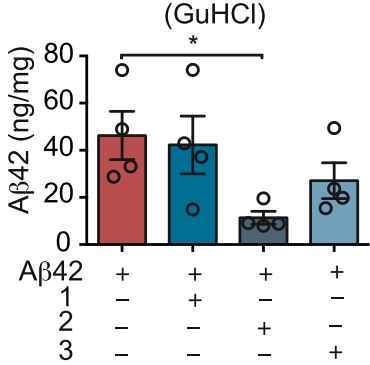

g

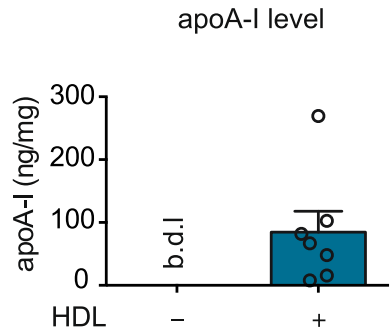

h

Tissue apoA-I level

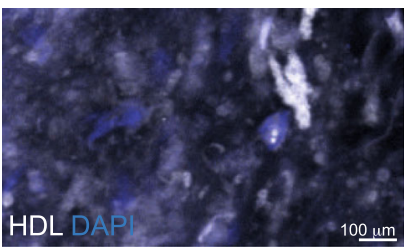

Fig. $2 \mathrm{HDL}$, but not $L D L$, reduces $A \beta 42$ accumulation in the bioengineered vessels by penetrating in the vascular wall. a $A \beta 42$ monomers (1 $\mu M)$ were injected into the tissue chamber concomitantly with circulating $200 \mathrm{\mu g} / \mathrm{mL}$ (total protein) of HDL or mixLDL (LDL, VLDL and ILDL) through the lumen. After $24 \mathrm{~h}$, tissues were lysed in RIPA and Aß42 was measured using ELISA. After injection of A 342 as above, $\mathrm{HDL}(200 \mu \mathrm{g} / \mathrm{mL})$ was circulated through the lumen and $A \beta 42$ accumulation was measured after $6 \mathrm{~h}(\mathbf{b})$ or $72 \mathrm{~h}(\mathbf{c})$. $\mathbf{d}$ Schematic representation of the experimental design for panels $(\mathbf{e})$ and $(\mathbf{f})$. Bioengineered vessels were treated with $A \beta 42$ with or without $\mathrm{HDL}$ (1) or pre-treated with $200 \mathrm{\mu g} / \mathrm{mL} \mathrm{HDL}$ for $24 \mathrm{~h}$ before injecting $A \beta 42$ without (2) or with (3) washing. $24 \mathrm{~h}$ after A 42 injection, A 3 accumulation was measured in RIPA (e) or GuHCl (f) fractions. $\mathbf{g ~ H D L ~}(200 \mathrm{\mu g} / \mathrm{mL})$ was circulated through lumen of bioengineered vessels for $24 \mathrm{~h}$ before measuring apoA-l in vascular tissues using ELISA. $\mathbf{h}$ Alexa 633-labeled HDL (depicted in white) was circulated through the circulation of engineered vessel before, washing, fixing and imaging using confocal microscopy, representative image of three bioengineered vessels. Points in graphed data represent individual bioengineered vessels, bars represent mean, error bars represent \pm SEM and analysed by Student's t-test or one way ANOVA ${ }^{*} P<0.05,{ }^{* *} P<0.01,{ }^{* *} P<0.001$ and ${ }^{* * *} P<0.0001$

vascular accumulation when tested $6 \mathrm{~h}$ after $A \beta 42$ injection (Fig. 2b) but maintains the significant 2 -fold reduction of $\mathrm{A} \beta 42$ accumulation up to $72 \mathrm{~h}$ (Fig. 2c), we hypothesised that HDL requires time, possibly to prime the vascular wall, to reduce $\mathrm{A} \beta$ accumulation.
To test this hypothesis, we compared the effect of HDL circulated prior to or concomitantly with injection of $\mathrm{A} \beta 42$ (Fig. 2d), and observed a stronger reduction in the RIPA-soluble A 342 fraction when HDL was circulated $24 \mathrm{~h}$ prior to injecting $A \beta 42$, with three out of four 
tissues below the detection limit of the ELISA, compared to HDL/A 342 co-treatment (Fig. 2e). Interestingly, we observed that pre-treatment with $\mathrm{HDL}$ also reduced A 342 accumulation in the $\mathrm{GuHCl}$-soluble fraction by 4fold compared to vehicle control, respectively (Fig. 2f). We then tested whether washing out HDL after $24 \mathrm{~h}$ of circulation affected vascular $A \beta 42$ accumulation. Interestingly, A $\beta 42$ accumulation in the RIPA fraction was reduced to a similar extent as when HDL was maintained in the circulation, with two out of four samples below the detection limit of the ELISA (Fig. 2e). A $\beta 42$ accumulation in the $\mathrm{GuHCl}$-soluble fraction tended to be reduced by 1.7 -fold compared to vehicle control after HDL wash-out (Fig. 2f). Together, these results suggest that HDL primes the vasculature to resist $A \beta 42$ accumulation, potentially by some component(s) of HDL penetrating the vascular wall.

\section{$\mathrm{HDL}$ enters the vasculature and reduces $A \beta 42$ uptake by vascular SMC}

The presence of HDL-associated apolipoproteins in the wall of human cerebral arteries with and without CAA has been demonstrated using both proteomic [45] and immunohistochemistry methods, and show that apoA-I, apoJ and apoE co-localize with CAA in human cerebral arteries [46]. Although apoE and apoJ are both expressed in the brain and found in the peripheral circulation, apoA-I is not expressed within the brain as it is secreted exclusively from hepatocytes and enterocytes [47]. As expected, bioengineered vessels have no detectable apoA-I when HDL is absent, and have an average of 84 ng of apoA-I per mg of total tissue protein after circulating HDL for $24 \mathrm{~h}$ (Fig. $2 \mathrm{~g}$ ), demonstrating that at least the apoA-I moiety on HDL particles can enter the engineered vascular wall. Further, fluorescently labeled HDL (fluorescent dye bound to protein moiety) accumulates in bioengineered vessels (Fig. 2h).

Our previous studies demonstrated that HDL reduces A $\beta 42$ uptake into EC [32]. Here, we used flow cytometry experiments to show that HDL also blocks $A \beta 42$ uptake into SMC, but with a kinetic difference compared to EC uptake. Specifically, SMC cultured in regular 2D tissue culture plates take up FITC-A $\beta 42$ after $24 \mathrm{~h}$ but not after $3 \mathrm{~h}$, indicating a slower uptake of $\mathrm{A} \beta 42$ into SMC compared to EC (Fig. 3a-b and Sup. Fig. 4a-b). Furthermore, after $24 \mathrm{~h}$, the median fluorescent signal was increased only by 1.7 -fold in SMC but was elevated by 9.2 -fold in EC suggesting less overall uptake of $A \beta 42$ into SMC compared to EC (Fig. 3a-b and Sup. Fig. 4a-b). After 24 $h$ in the presence of HDL, FITC-A $\beta 42$ uptake remains at background levels, demonstrating that HDL blocks A $\beta 42$ uptake in SMC (Fig. 3a-b). These results were further confirmed by microscopy (Fig. 3c). We also showed that the reduced fluorescent intensity of FITC-A 442 after
HDL treatment was not due to increased colocalization with the lysosomal marker LAMP1, which would suggest enhanced degradation after HDL treatment (Sup. Fig. 4c).

We next assessed the role of the low density lipoprotein related protein (LRP)1, the major $A \beta$ binding partner in SMC [48], by measuring LRP1 protein levels after HDL treatment. Although HDL reduced LRP1 levels after $24 \mathrm{~h}$ in SMC in regular tissue culture plates (Fig. 3d), it did not affect LRP1 levels in bioengineered vessels at the $24 \mathrm{~h}$ time point (Fig. 3e), However circulating recombinant receptor associated protein (RAP) through the lumen of bioengineered vessels to block LRP1 led to a significant 8-fold reduction in $A \beta 42$ accumulation, similar to the effects observed with HDL (Fig. 3f). Taken together these results suggest that blocking $A \beta$ uptake into SMC via LRP1 reduces vascular $A \beta 42$ accumulation in bioengineered vessels.

Several experiments were performed to determine if HDL affects "blood-to-brain" transport of $A \beta$. Entry of $A \beta$ from the periphery into the brain is mediated by the receptor for advanced glycation endproducts (RAGE) [49] and has been reported to cause both parenchymal and CAA pathologies [50, 51]. Although we observed that RAGE levels in engineered tissues were increased 2-fold upon HDL treatment, approaching significance (Sup. Fig. 5a), A $\beta$ accumulation is reduced in the presence of HDL. We also tested whether HDL blocks accumulation of circulating $\mathrm{A} \beta 42$ by directly comparing $\mathrm{A} \beta 42$ accumulation in bioengineered vessels when $A \beta 42$ was injected in the antelumen chamber or into the circulation loop at a final concentration of $1 \mu \mathrm{M}$. As expected, after $24 \mathrm{~h}, \mathrm{~A} \beta 42$ levels were higher in the chamber into which it was injected. Specifically, injection of $A \beta 42$ into the tissue chamber resulted in 5-fold higher A $\beta 42$ levels in the tissue chamber media compared to the circulating media (Sup. Fig. 5b), whereas injection into the circulation loop resulted in 5.5-fold higher $A \beta$ levels in the circulating media compared to the tissue chamber media (Sup. Fig. 5c), demonstrating that A 342 does not diffuse across the bioengineered vessels. After $24 \mathrm{~h}$, we observed that vascular accumulation of $A \beta 42$ was 3-fold higher when $A \beta 42$ was injected into the antelumen chamber compared to the circulation loop, and that HDL only reduced $A \beta 42$ vascular tissue accumulation when $A \beta 42$ was injected in the antelumen chamber (Sup. Fig. 5d). We further investigated if blocking peripheral A $\beta 42$ uptake using a RAGE antibody altered A $\beta 42$ accumulation and found no effect (Sup. Fig. 5e).

\section{$A \beta$ co-localizes with collagen-I in human post-mortem CAA and HDL reduces collagen-I expression in monolayer SMC cultures}

As treating 2D cultures of SMC with $A \beta 42$ leads to a staining pattern that does not resemble the vesicular like-shape of typical intracellular staining (Fig. 3c), we 

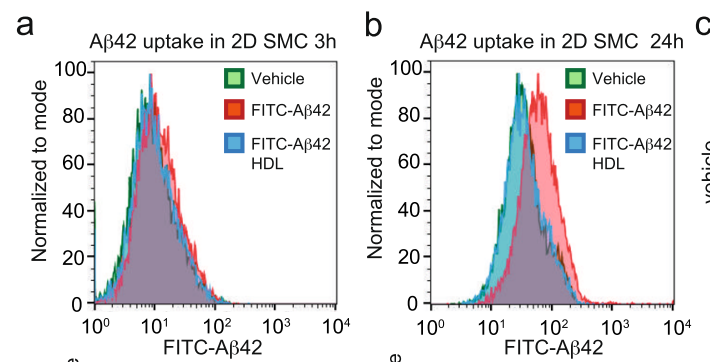

C $2 \mathrm{D} \mathrm{SMC}$
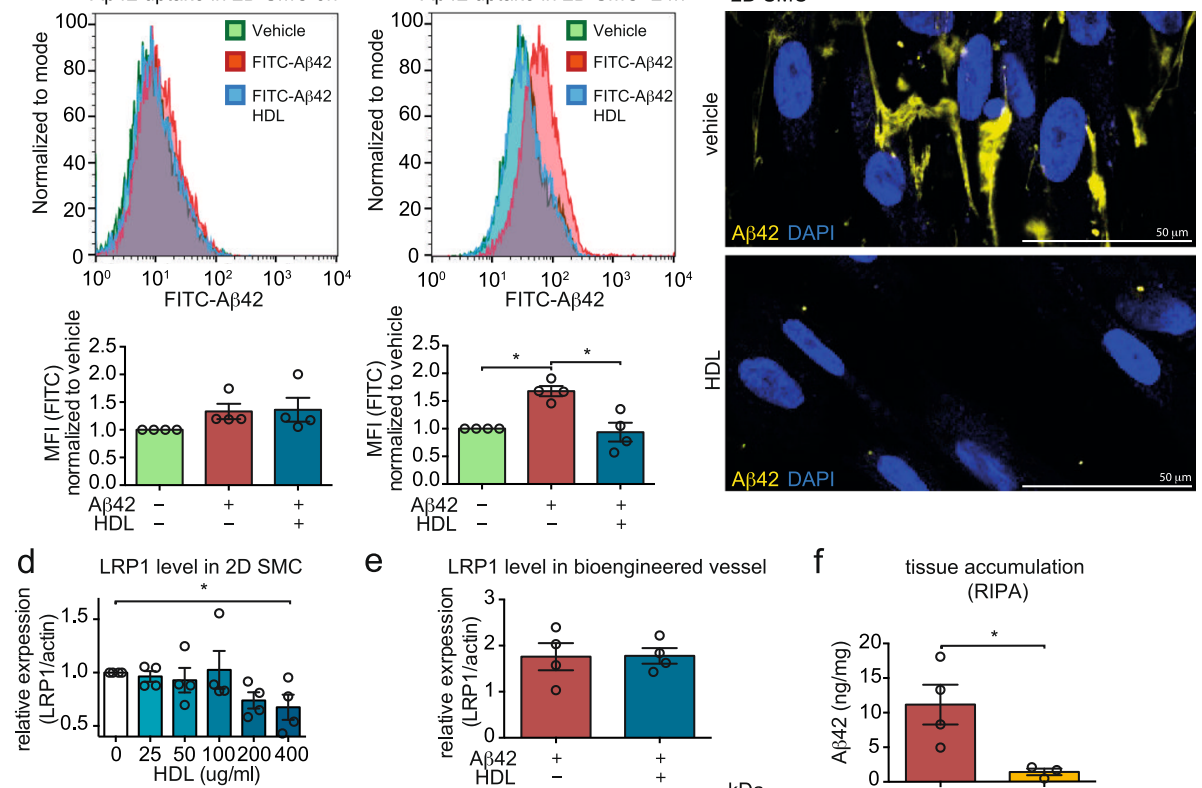

e
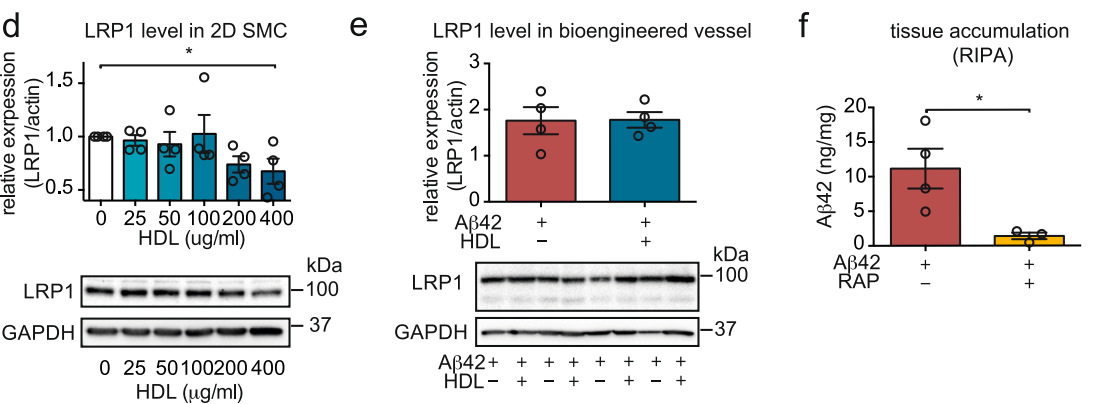

$\mathrm{HDL}+-++++$

Fig. $3 \mathrm{HDL}$ reduces $A \beta 42$ uptake and LRP1 levels in SMC and blocking LRP1 with RAP reduces AB42 accumulation in bioengineered vessels. SMC were grown as 2D monolayers for $2 \mathrm{~d}$ before treating with $1 \mu \mathrm{M}$ FITC-A 342 without or with $200 \mu \mathrm{g} / \mathrm{mL}$ of HDL for $3 \mathrm{~h}$ (a) or $24 \mathrm{~h}$ (b) before dissociating the cells and counting using flow cytometry. c SMC were grown in $2 \mathrm{D}$ culture for $3 \mathrm{~d}$ before treating with FITC-A $\mathrm{A} 42(5 \mu \mathrm{M}$, yellow) with $200 \mu \mathrm{g} / \mathrm{mL}$ of HDL or BSA for $24 \mathrm{~h}$ and imaged using microscopy. $\mathbf{d}$ SMC were grown for 3 days in $2 \mathrm{D}$ culture were treated with the indicated HDL concentration. LRP1 protein levels were measured by Western blot and normalized to GAPDH. e Aß42 monomers (1 $\mu \mathrm{M})$ were injected into the tissue chamber concomitantly with circulating $200 \mu \mathrm{g} / \mathrm{mL}$ of HDL or BSA through the lumen. After $24 \mathrm{~h}$, tissues were lysed in RIPA. LRP1 protein levels were measured in bioengineered vessels using Western blot and normalized to GAPDH. $\mathbf{f}$ Bioengineered vessels were treated with $1 \mu \mathrm{M}$ A 342 with or without recombinant RAP in the circulation media to block LRP1. After $24 \mathrm{~h}$, tissues were lysed in RIPA and Aß42 accumulation was measured by ELISA. Points in graphed data represent individual bioengineered vessels, bars represent mean, error bars represent \pm SEM and analysed by Student's t-test or one way ANOVA $* P<0.05$

next investigated whether $\mathrm{A} \beta 42$ is taken up by SMC or whether it remains bound to the cell membrane or extracellular matrix (ECM) produced by SMC. Fluorescent analysis using fluorochrome-coupled wheat germ agglutinin (WGA) to delineate the cell membrane and anti-collagen-I to stain the ECM showed that the A 442 signal was both extracellular (magenta arrows) and intracellular (yellow arrows) (Fig. 4a). We further used immunofluorescence staining to determine whether $\mathrm{A} \beta$ co-localizes with vascular ECM proteins in post mortem human brain (cortex Brodmann area 9). We found that A $\beta$ co-localized with collagen-I in the vascular wall (Fig. 4b1) but not in parenchymal plaques (Fig. 4b2) and observed punctuate staining in the periphery of the plaques (arrows) in half of the patient brains tested. Vascular $\mathrm{A} \beta$ also partially colocalized with collagen-IV but not with laminin, which was located closer to the lumen of the vessels (Sup. Fig. 6a-b). Finally, we tested whether $A \beta$ co-localizes with proteoglycans such as biglycan (Sup. Fig. 6c), heparan sulphate proteoglycan 2 (HSP2)/perlecan (Sup. Fig. 6d) and versican
(Sup. Fig. 6e) and found that only vascular $A \beta$ colocalized with these proteoglycans. We then investigated $A \beta 42$ co-localization with the ECM in engineered vessels and found that $A \beta 42$ co-localized with collagenI (white arrows) (Fig. 4c).

Because a previous study suggested that HDL reduces collagen-I levels in mouse aortic SMC [52], we evaluated FITC-A $\beta 42$ and collagen-I levels in sub-confluent SMC cultured in regular $2 \mathrm{D}$ plates in the absence or presence of HDL and observed lower signals for both FITC-A $\beta 42$ and collagen-I staining $24 \mathrm{~h}$ after HDL treatment (Fig. 4d). We confirmed these results by Western blotting to show that HDL reduced collagen-I protein levels in SMC by 2-fold compared to vehicle control, whereas A 342 did not alter collagen-I levels (Fig. 4e). Interestingly, collagen-I levels were not altered in bioengineered vessels after $24 \mathrm{~h} \mathrm{HDL}$ treatment (Fig. 4f), suggesting that a reduction in collagen-I levels is unlikely to explain the mechanism of action of HDL on accumulation of A 342 in bioengineered vessels at acute time points. 


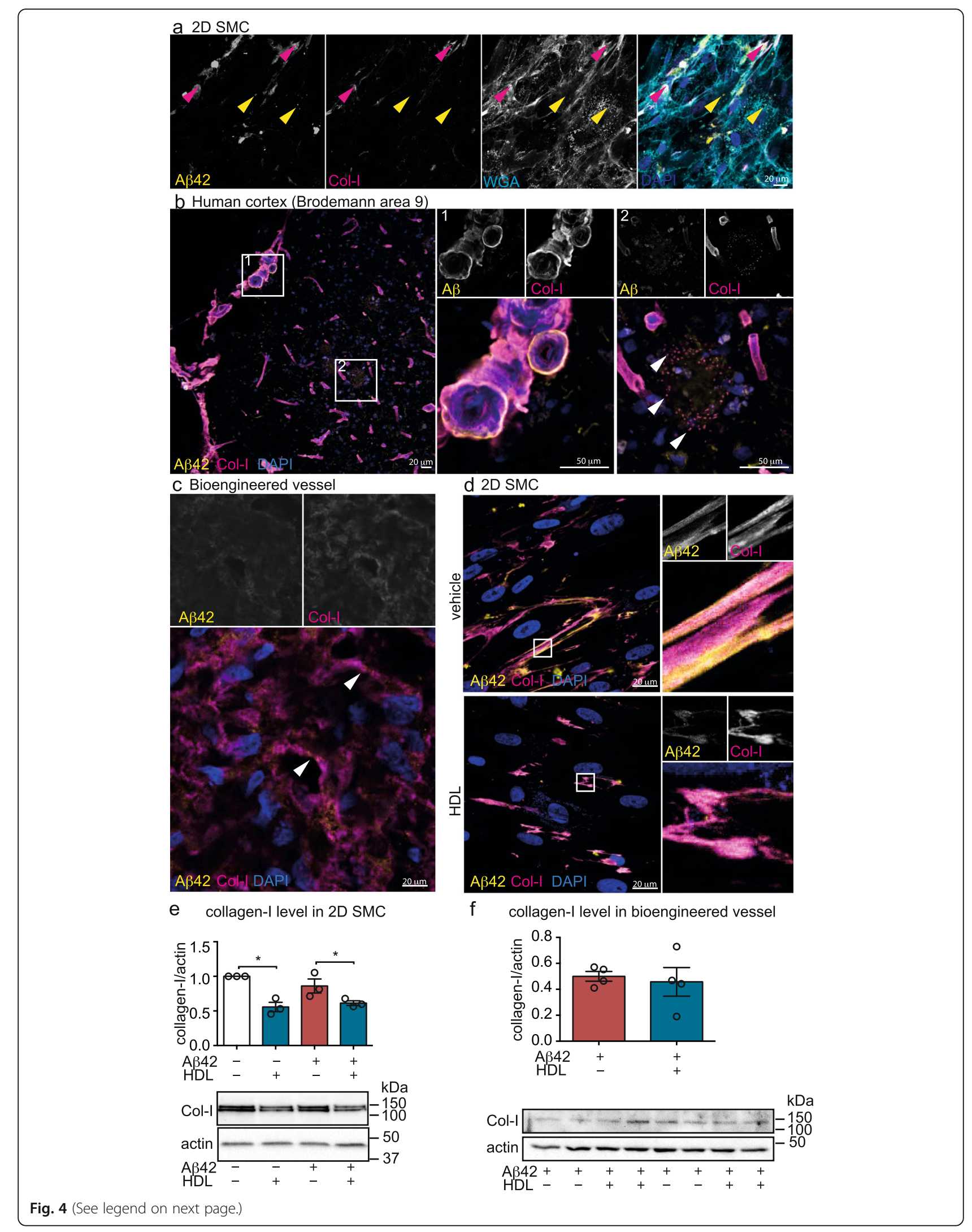


(See figure on previous page.)

Fig. 4 A 42 binds to collagen-I in the vascular wall of post-mortem human brain and in bioengineered vessels and HDL reduces collagen-l level in SMC. a SMC were grown for $1 \mathrm{~d}$ in chamber slides before treating with $0.5 \mu \mathrm{M}$ FITC-Aß42 (yellow) and $200 \mu \mathrm{g} / \mathrm{ml} \mathrm{HDL}$. After $24 \mathrm{~h}$, cells were fixed and cell membranes were stained using wheat germ agglutinin (WGA, magenta) and an antibody against collagen-I (cyan) was used to stain the ECM. Yellow arrows show intracellular A 42 and magenta arrows show collagen-1/Aß42 co-localization. b Human cortex (Brodmann area 9) from four donors was stained for A $\beta$ using 6E10 (yellow) and collagen-I (magenta) and expanded views of vascular (1) and cortical (2) AB fibrillar plaques are presented on the right. c Bioengineered vessels treated with A 342 monomers for $24 \mathrm{~h}$ were stained for collagen-I (yellow) and $A \beta$ (6E10, magenta). White arrows show co-localization of collagen-I and A 42 . $\mathbf{d}$ SMC were grown on 2D coverslips for $24 \mathrm{~h}$ before incubating with $0.5 \mu \mathrm{M}$ FITC-A 42 (yellow) and $200 \mu \mathrm{g} / \mathrm{mL}$ HDL. SMC were then fixed and stained for collagen-I (magenta). Details of collagen-I fibres and $A \beta 42$ co-localization are presented on the right. e SMC were grown for $24 \mathrm{~h}$ in $2 \mathrm{D}$ culture before treating with $1 \mu \mathrm{M} A \beta 42$ with or without $200 \mu \mathrm{g} / \mathrm{mL} \mathrm{HDL}$. After $24 \mathrm{~h}$, cells were lysed, collagen-l expression was measured by Western blot and normalized to actin levels. $\mathbf{f}$ Bioengineered vessels were treated with $1 \mu \mathrm{M}$ A 342 and $200 \mu \mathrm{g} / \mathrm{mL} \mathrm{HDL}$ as above. After $24 \mathrm{~h}$, bioengineered vessels were lysed in RIPA and collagen-l levels were measured by Western blot and normalized to actin levels. All images are representative of at least 3 individual experiments or 4 donors and were imaged using confocal microscopy. Points in graphed data represent individual bioengineered vessels, bars represent mean, error bars represent \pm SEM and analysed by Student's t-test ${ }^{*} P<0.05$

\section{$H D L$ reduces $A \beta 42$ binding to collagen-I by forming a complex}

As we previously reported that the staining pattern of HDL in the vascular wall is similar to the ECM pattern [37], we tested whether HDL might compete with and prevent A $\beta 42$ binding to collagen-I fibres. First, we cultured SMC for 3 days in 2D chamber slides to allow time for ECM deposition. SMC were then incubated with FITC-A $\beta 42$ with or without fluorochrome-labeled HDL before immunostaining for collagen-I. We confirmed that FITC-A $\beta 42$ bound to collagen-I and demonstrated that HDL partially co-localized with collagen-I (arrows) (Fig. 5a). We next used a cell-free assay where 96-well plates were coated with either rat-tail collagen-I or BSA as a control and incubated with FITC-A $\beta 42$ with or without HDL for $24 \mathrm{~h}$. We showed that A $\beta 42$ binding to collagen-I was 3-fold higher than the BSA control and that $\mathrm{HDL}$ reduced $\mathrm{A} \beta 42$ binding to both $\mathrm{BSA}$ and collagen-I by 11.8 - and 7-fold, respectively (Fig. 5b). These data suggest that HDL may help maintain $\mathrm{A} \beta 42$ in solution not only by competing for binding to collagen-I but also by forming a complex with $A \beta$. We confirmed the formation of an A $\beta 42 / \mathrm{HDL}$ complex using gel-filtration chromatography and fraction analysis in a dot blot immunoassay. After incubating $A \beta 42$ with either HDL or BSA as a protein control, mixtures were separated by size exclusion and fractions were dotted onto nitrocellulose and probed for $\mathrm{A} \beta$ and apoA-II, a representative HDL protein. The UV spectrum analysis did not reveal major differences between HDL with or without A $\beta 42$ (Sup. Fig. 7a-c). Conversely, densitometry analysis of the dot blots demonstrated that the A $\beta 42$ elution distribution range was increased after incubation with HDL and that A $\beta 42$ co-distributed with HDL fractions (Fig. 5c). Importantly, untreated HDL fractions were negative for $\mathrm{A} \beta 42$ (Sup. Fig. 7a). We further confirmed the formation of a complex by measuring a subtle but significant decrease in cholesterol efflux from
RAW264.7 macrophages to $\mathrm{HDL}+\mathrm{A} \beta 42$ compared to HDL alone (Sup. Fig. 7d). Incubating lipid-free apoA-I with $\mathrm{A} \beta 42$ also reduced cholesterol efflux activity compared to apoA-I alone, suggesting that the A $\beta 42 / \mathrm{HDL}$ complex might be preferentially associated with the protein moiety of HDL (Sup. Fig. 7e). A 342 alone did not alter basal cholesterol efflux activity (Sup. Fig. 7f).

We then hypothesised that if HDL acts to maintain A 342 solubility in the vascular wall, we should observe an increase in A $\beta 42$ levels in vascular extracellular fluid (TBS soluble fraction) and enhanced $A \beta 42$ recovery in the circulating media after HDL treatment due to more efficient transport through the vascular wall. Although not significant, the concentration of $A \beta 42$ in the TBSsoluble fraction was increased by 2 -fold $24 \mathrm{~h}$ after HDL treatment, while $A \beta 42$ levels in circulating media were significantly increased by 8.8 -fold after HDL treatment (Fig. 5d-e). These observations strongly suggest that HDL reduces $A \beta$ accumulation by increasing "brain-toblood" transport of soluble A $\beta 42$ through the vascular wall to the circulation.

\section{ApoE-containing HDL particles reduce vascular $A \beta 42$ accumulation more effectively than apoE-depleted HDL}

As HDL does not affect total collagen-I levels in engineered vessels after $24 \mathrm{~h}$ yet HDL binds to collagen-I, we next used Native-PAGE and immunoblotting to determine if HDL affects collagen-I migration. After circulating HDL through the vessel for $24 \mathrm{~h}$, collagenI migrated as species of $\sim 100 \mathrm{kDa}$, which is smaller than the typical triple helix structure of collagen-I that is too big to enter the acrylamide stacking gel $(\sim 520 \mathrm{kDa})$ [53]. Interestingly, these smaller collagenI species co-migrated through Native-PAGE gels with apoE-HDL and apoA-II-HDL particles, whereas apoAI-HDL particles have a smaller size (Fig. 5f). We then hypothesised that the apolipoprotein composition of HDL may affect A $\beta 42$ vascular accumulation. We 


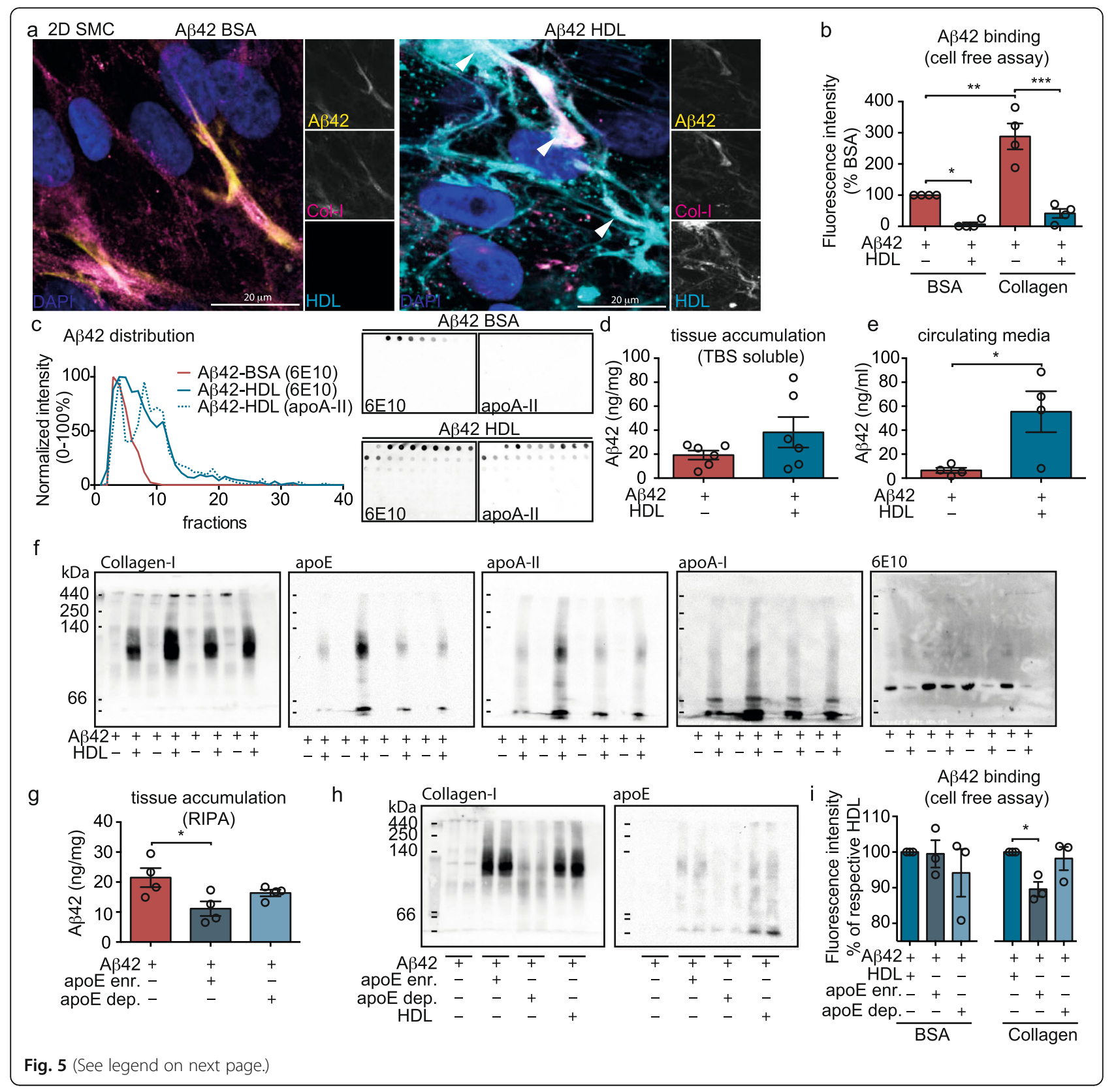


(See figure on previous page.)

Fig. $5 \mathrm{HDL}$ binds to both collagen-I and to $A \beta 42$ to form a complex and increases $A \beta$ transport through the bioengineered vessel wall primarily by HDL-apoE particles. a SMC were grown for $3 \mathrm{~d}$ on 2D coverslips before incubating with $0.5 \mu \mathrm{M}$ FITC-Aß42 (depicted as yellow) and $200 \mu \mathrm{g} / \mathrm{ml}$ Alexa-633 labeled HDL (depicted as cyan). After $24 \mathrm{~h}$, cells were fixed and stained for collagen-I (magenta) before imaging by confocal microscopy. White arrows show co-localization of Aß42, HDL and collagen-l. b Black 96 well-plates were coated either with $50 \mu \mathrm{g} / \mathrm{mL}$ rat-tail collagen-I or $10 \% \mathrm{BSA}$ as protein control for $24 \mathrm{~h}$ before incubating with a solution of $1 \mu \mathrm{M}$ of FITC-Aß42 with or without $200 \mu \mathrm{g} / \mathrm{mL}$ of HDL. After $24 \mathrm{~h}$ and extensive PBS washes, fluorescence representing bound A 42 was measured at $520 \mathrm{~nm}$, excitation $490 \mathrm{~nm}$. c $1 \mu \mathrm{M}$ A $342 \mathrm{were}$ incubated either with $200 \mathrm{\mu g} / \mathrm{mL}$ of $\mathrm{HDL}$ or BSA for $24 \mathrm{~h}$ at $37^{\circ} \mathrm{C}$ before gel-filtration chromatography separation. Fractions were dot blotted and immunodetected for AB (6E10) or HDL (apoA-II). The intensity of each fraction on the dot blot was quantified, normalized between 0 and $100 \%$ and graphed on the left panel. The right panel shows a representative dot blot used for quantification. $\mathbf{d} 1 \mu \mathrm{M}$ A 342 was injected in the tissue chamber of bioengineered vessels and $200 \mu \mathrm{g} / \mathrm{mL}$ of HDL was circulated through the lumen. After $24 \mathrm{~h}$, tissues were homogenized in TBS to collect soluble $A \beta$, which was quantified in the tissue (c) or circulating media (d) by ELISA. f $1 \mu \mathrm{M} A \beta 42$ was injected in the tissue chamber of bioengineered vessels and $200 \mathrm{\mu g} / \mathrm{mL}$ of $\mathrm{HDL}$ was circulated through the lumen. After $24 \mathrm{~h}$ vessels were lysed in RIPA and protein distribution was analysed using non-denaturing native blot probed for collagen-I, apoE, apoA-II, apoA-I and Aß (6E10). $\mathbf{g} \mathrm{HDL}$ was enriched for or depleted of apoE using an apoE immunoaffinity column. Bioengineered vessels were then treated with either fraction $(200 \mu \mathrm{g} / \mathrm{mL})$ in the presence of $1 \mu \mathrm{M}$ $A \beta 42$ as above before measuring A $\beta$ deposition in the RIPA-soluble fraction. $\mathbf{h}$ RIPA lysates from engineered vessels were then analysed using non-denaturing native blot probed for collagen-I and apoE. i Black 96-well plates were coated either with $50 \mu \mathrm{g} / \mathrm{mL}$ rat-tail collagen-I or $10 \%$ BSA for $24 \mathrm{~h}$ before incubating with a solution of $1 \mu \mathrm{M}$ of FITC-Aß42 with or without $200 \mu \mathrm{g} / \mathrm{ml}$ of total HDL, apoE-depleted HDL or apoE-enriched HDL. After $24 \mathrm{~h}$ and extensive PBS washes, fluorescence was measured at $520 \mathrm{~nm}$, excitation $490 \mathrm{~nm}$. FPLC data and Western blots are representative of at least 3 individual experiments. Points in graphed data represent individual bioengineered vessels, bars represent mean, error bars represent \pm SEM and analysed by Student's t-test or one way ANOVA ${ }^{*} P<0.05,{ }^{* *} P<0.01,{ }^{* * *} P<0.001$ and ${ }^{* * *} P<0.0001$

prepared apoE-depleted or apoE-enriched HDL using an apoE immunoaffinity column. When normalized to apoA-I levels, apoE-depleted HDL had 4-fold lower and apoE-enriched HDL had 30-fold higher apoE levels than total plasma HDL (not shown). After circulating $200 \mu \mathrm{g} /$ $\mathrm{mL}$ (total protein) of these HDL fractions (corresponding to equivalent apoA-I concentrations) through the lumen of bioengineered vessels we observed that apoE-depleted HDL reduced A $\beta 42$ accumulation only by 1.3 -fold, whereas apoE-enriched HDL caused a significant 2-fold reduction (Fig. 5g). Further, only apoE-enriched HDL affected the migration of collagen-I through Native-PAGE gels (Fig. 5h). Finally, we used the cell-free collagenbinding assay to show that apoE-enriched HDL reduced A 342 binding to collagen more effectively than apoEdepleted HDL (Fig. 5i).

\section{Bioengineered tripartite vessels with astrocytes exhibit lower $A \beta 42$ accumulation, native apoE in the tissue chamber media, and reduced A $\beta 42$ binding to collagen-I}

Bioengineered vessels similar to cortical penetrating arteries were fabricated using primary human EC, SMC and astrocytes (Fig. 6a). We previously reported that vessels lacking astrocytes (bipartite tissues) accumulate more $A \beta 42$ than tissue with astrocytes (tripartite tissues) [31], which we confirmed here (Fig. 6b). We previously hypothesised that this difference might be due to increased apoE levels in tissues with astrocytes [31]. Here we tested whether apoE secreted by astrocytes might also reduce $A \beta 42$ binding to collagen-I. After tissue homogenization, fractionation by SDS-PAGE and immunoblotting, we first confirmed that astrocyte-secreted apoE was increased by 1.5 -fold in the tissue and 2 -fold in the antelumen chamber but not in the circulation media as measured by ELISA (Fig. 6c-d), confirming that native astrocyte-secreted apoE does not cross the EC barrier in bioengineered vessels. We then tested whether conditioned media extracted from the antelumen chamber or circulation of bi- and tripartite tissues reduces A $\beta 42$ binding to collagen-I. We found that tripartite antelumen chamber media significantly reduced $A \beta 42$ binding to collagen-I compared to bipartite chamber media whereas no differences were observed with circulation media. Finally, we found no differences when comparing $A \beta 42$ binding to the protein vehicle control BSA (Fig. 6e). Together, these data suggest that apoE, and/or other factors, secreted by astrocytes prevents binding of $A \beta$ to vascular collagen-I, thereby reducing CAA in bioengineered vessels.

\section{Discussion}

ApoE is the major genetic risk factor for late onset $A D$ and plays multiple roles in $\mathrm{AD}$ pathogenesis including brain lipid transport, regulation of $A \beta$ aggregation and clearance, neuronal function and signalling, cerebrovascular integrity, glucose metabolism, neuroinflammation, and mitochondrial function [34]. For decades, apoE has been presumed to affect $\mathrm{AD}$ through its production and actions within the brain, as apoE is the major apolipoprotein secreted by astrocytes, microglia, pericytes and stressed neurons [34]. Although apoE is also produced by the liver and peripheral tissue macrophages, findings from liver transplant patients showed that apoE does not cross the blood-brain barrier and, as such, the brain and plasma pools of apoE are distinct [54]. Potential roles for peripheral apoE in $\mathrm{AD}$ have therefore been 


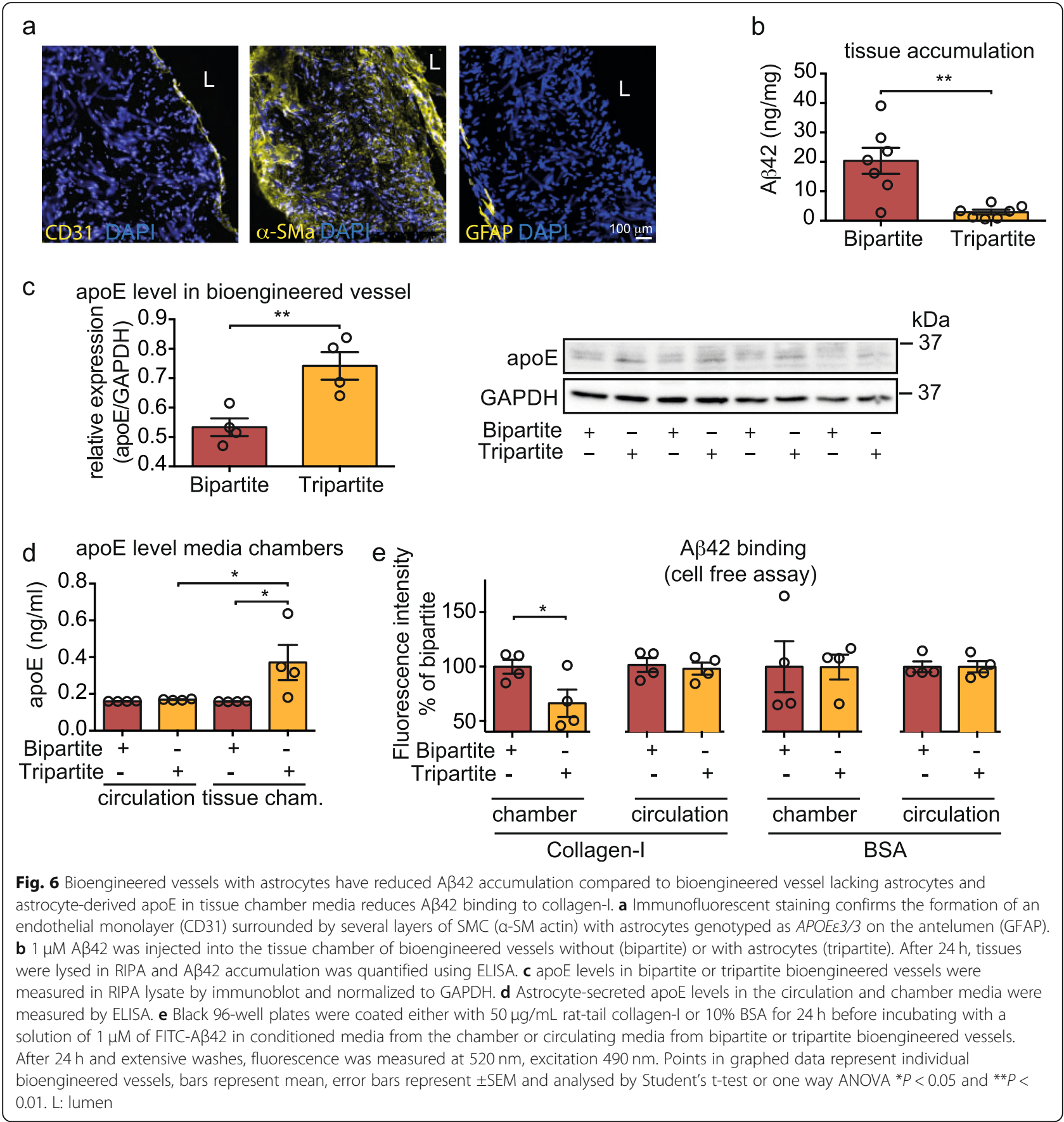

understudied. Here we show that, as part of circulating HDL complexes, peripheral apoE can significantly reduce CAA in bioengineered vessels, raising the hypothesis that apoE-enriched HDL particles may promote vascular resilience to $A \beta$. Our results support new perspectives on apoE's role in $\mathrm{AD}$ pathogenesis, including: 1) that circulating apoE may play a greater role in $A \beta$ clearance than previously appreciated, and 2) that interventions based on apoE-enriched HDL may be effective in promoting $A \beta$ clearance across the vascular wall, raising the possibility of a systemic preventative, companion or therapeutic approach for AD.

This study defines multiple mechanisms by which HDL promotes cerebrovascular health in the context of $A D$, with a focus on the capacity of HDL to reduce $A \beta$ accumulation in the vascular wall. We first demonstrated that HDL acts independently of SR-BI to 
decrease vascular $A \beta$ accumulation, which is in contrast to the SR-BI dependent mechanism by which HDL reduces A $\beta$-induced inflammation [32], representing a major bifurcation in mechanism along the antiinflammatory and anti-CAA effects of HDL. These data are aligned with previous studies reporting increased perivascular macrophages in the brains of $\mathrm{SR}-\mathrm{BI}^{+/-}$and SR-BI ${ }^{-/}$mice [55]. Additional supporting evidence for the role of SR-BI includes enhanced $A \beta$ deposition in the brain and cerebrovasculature due to defective $A \beta$ clearance by perivascular macrophages in J20 AD mice on an SR-BI ${ }^{+/-}$background [55]. Here we used human bioengineered vessels to show that blocking SR-BI does not diminish the ability of HDL to reduce vascular A $\beta 42$ accumulation in the absence of circulating monocytes and perivascular macrophages, suggesting that SR-BI may be a key player in the inflammatory response to $A \beta$ in the vascular wall. Further work will be needed to specifically understand the role of transmigrating monocytes and perivascular macrophages in CAA and $A \beta$ clearance in both human and animal model systems, to further refine our understanding of the roles of HDL and SR-BI in this process.

With respect to CAA, our findings support four pathways by which HDL contributes to reduced vascular $A \beta$ deposition, namely i) reducing $A \beta$ binding to collagenI, ii) reducing collagen-I production from SMC, and iii) forming a complex that maintains $A \beta$ in a soluble state, and iv) reducing $A \beta$ uptake into SMC that may be associated with reduced LRP1 protein levels or other to-be-defined mechanisms. Importantly, some of these processes depend on the apoE content of HDL particles. As a first step, we found that HDL needs to enter the vascular wall to affect SMC and interact with the ECM, however, exactly how HDL and HDL-associated lipoproteins enter the cerebrovascular wall remains to be elucidated. Once in the vascular wall, one mechanism by which HDL may attenuate $A \beta$ deposition in the vasculature is by reducing LRP1-mediated $A \beta$ uptake into SMC. We showed that HDL modestly reduces LRP1 levels in SMC monolayer cultures yet we did not observe this phenomenon in bioengineered vessels. We hypothesize that differences in culture times and culture complexity might underlie this discrepancy. Specifically, SMC are cultured alone in 2D culture for days whereas in bioengineered vessels, SMC are co-cultured with EC for several weeks and thus have an extended time to produce vascular ECM [37]. A subtle decrease in LRP1 level as observed in 2D might easily be lost in the increased complexity of 3D culture. Still, blocking LRP1 using RAP decreased the accumulation of RIPA-soluble $A \beta 42$ in engineered vessels, suggesting that preventing $A \beta$ uptake into SMC may promote its acute clearance through the vessel wall.
However, this pathway may be a minor mechanism, as only a small proportion of $\mathrm{A} \beta 42$ was taken up by SMC whereas the vast majority is bound to the ECM produced by SMC. Using co-localization studies in human $\mathrm{AD}$ cortex, we showed that vascular $\mathrm{A} \beta$ was primarily located outside of the cerebrovascular cells and associated with ECM matrix, in particular collagen-I. We did not observe specific vesicular staining in the vasculature of human cortical samples that would suggest uptake by SMC. We previously reported that HDL did not alter LRP1 protein levels in EC [32]. Although a previous study reported that blocking LRP1-mediated $A \beta 42$ uptake by SMC reduces cell death and decreases CAA risk [56], another study reported that $\mathrm{LRP}^{-/-}$mice have increased vascular $\mathrm{A} \beta$ accumulation [48]. Furthermore, Bell and colleagues elegantly showed that overexpression of serum response factor and myocardin in SMC reduces LRP1 expression, induces arterial hypercontractility, and reduces cerebral blood flow (CBF), ultimately leading to increased CAA in mice [57]. The discrepancy might be explained by differences in experimental design, as we investigated acute responses in our human bioengineered vessel compared to monitoring outcomes for several months for the murine studies. We also focused on only one $A \beta$ species in our study. Further studies on the role of LRP1, specially using cell-type specific $\mathrm{LRP}^{-/-}$models, will be needed to understand both the short- and long-term roles of LRP1 on the uptake of different species of $A \beta$ by SMC and EC in the vasculature.

With respect to HDL's effect on ECM, our results demonstrate that HDL significantly reduces collagen-I levels produced by SMC in $2 \mathrm{D}$ monoculture. We tested these effects in the presence and absence of $A \beta 42$ and confirm that, in both cases, collagen-I levels were significantly reduced, suggesting that HDL's effect on collagen expression operates independently of $A \beta 42$. Our observations are consistent with previous studies demonstrating that apoE-containing HDL decreases ECM gene expression in aortic SMC [52]. Here also, we did not observe a significant difference in collagen-I level in bioengineered vessels after HDL treatment. Again, we hypothesize that discrepancy between 2D monoculture and 3D bioengineered vessels might be explained by the different cultured conditions, as experiments in 2D culture were performed $24 \mathrm{~h}$ after seeding SMC when the cells are in a growth phase and start to secret collagen-I, whereas experiments utilizing 3D bioengineered vessels begin after SMC have been maintained in culture for at least a month. Previous studies have demonstrated that collagen-I deposits within the vascular wall of bioengineered vessels over time $[37,58]$. Because we measured collagen-I level only $24 \mathrm{~h}$ after HDL treatment, it is possible that collagenI levels are either more susceptible to be altered by HDL in 2D culture, or that HDL-modification of collagen-I 
levels in 3D bioengineered vessels requires more than $24 \mathrm{~h}$ to yield significant effects due to the relatively greater amount of deposited collagen-I in the 3D vs. $2 \mathrm{D}$ models. As HDL reduces CAA in bioengineered vessels within 24 $\mathrm{h}$ of treatment, we hypothesize that reduced collagen-I levels is unlikely to play a major acute role in reducing CAA, although lower collagen deposition over the long term could preserve vascular reactivity and thus maintain vascular and brain health. This is important as the cerebrovasculature stiffens during aging due to altered ECM composition with increased collagen and reduced elastin levels. Moreover, mild cognitively impaired and AD individuals have reduced cerebrovascular reactivity [59], indicative of increased vessel stiffness.

Our results demonstrate that HDL treatment alters collagen-I size distribution, which associates with the apoE and apoA-II moieties in HDL particles. Further, A $\beta 42$ accumulation, collagen-I size distribution and A $\beta 42$ binding to collagen-I are all dependent on the presence of apoE on HDL particles. These results are highly relevant as they support emerging hypotheses highlighting the role of peripheral apoE as an important contributor to the onset and progression of AD [60-62]. ApoE-containing HDL only represents 6 to $9 \%$ of total HDL particles in the plasma of normolipidemic individuals with the remaining apoE being associated with larger lipoproteins such as VLDL and LDL [33]. Here we show that a mixture of LDL, ILDL and VLDL fails to prevent $A \beta 42$ accumulation in engineered vessels, supporting the specificity of HDL particles in this process. Further work will be required to understand how apoEcontaining HDL particles specifically reduce CAA and if apoE isoforms differentially affect this process. Notably, mice expressing human apoE4 have disturbed perivascular drainage and increased vascular basement membrane collagen-IV levels at 3 months of age but decreased levels at 16 months of age compared to apoE3 mice [63]. $A P O E 4 / 4$ is also associated with a thinning of microvascular basement membrane [64] and altered ECM composition with deposition of fibrin(ogen) compared to APOE3/3 [65]. Importantly, whether brain-derived or peripheral apoE drives these vascular changes is not yet known.

As $A \beta 42$ is a hydrophobic peptide and HDL carries lipids, we also tested whether HDL and $A \beta 42$ can form a physical complex. Our gel-filtration chromatography experiments support this possibility, as elution fractions differed when A $\beta 42$ was incubated with HDL compared to $\mathrm{BSA}$ as a protein control, suggesting specific binding of $A \beta 42$ to HDL. Additionally, HDL complexed with A $\beta$ exhibited lower cholesterol efflux activity, suggesting that $\mathrm{A} \beta$ binding to HDL may compromise one of HDL's most well-described functions. Although these findings suggest that HDL can form a complex with $A \beta 42$, further work will be needed to establish the exact interaction mechanisms. Nevertheless, the formation of a potential HDL-A $\beta$ complex suggests that HDL could compete with and prevent A $\beta 42$ binding to collagen-I. In line with this finding, several groups report an interaction of HDL and $A \beta$, with HDL being the major binding partner of $A \beta$ fibrils in plasma $[22,66]$.

Finally, apoE-containing HDL has recently been established as a biomarker for coronary artery disease (CAD) risk [67]. As assays to selectively measure the proportion of HDL particles containing apoE become more readily available, it will be important to determine whether the levels of circulating apoE-containing HDL help to predict the risk of $C A A$, total brain $A \beta$ accumulation, and cognitive decline in AD patients.

Our study has several limitations. One is that we used readily obtainable umbilical cords to isolate the EC and SMC used to fabricate bioengineered vessels, as primary cerebrovascular EC have a slower growth rate and commercial supplies are limited compared to the demands of the bioengineered vascular model, and induced pluripotent stem cell (iPSC) EC have greater batch-to-batch variation during differentiation. Although cord-derived cells are not brain-like, several studies demonstrate that cord cells are plastic and can acquire specific organ features depending on the microenvironment in which they are cultured. In particular, several studies showed that HUVEC can become reprogrammed to express selective $\mathrm{BBB}$ marker proteins when cultured in the brain environment $[31,68,69]$. Furthermore, we previously showed that the histological structure as well as $A \beta$ accumulation and transport were similar between vessels bioengineered using primary human brain vascular cells vs. umbilical cord cells [31], raising confidence on the validity of our findings. A second limitation concerns the number of SMC layers, which is greater in bioengineered vessels compared to the few layers of SMC in human cerebral arteries [70]. While this difference might influence our results, it is important to note that both in post-mortem human tissues and in bioengineered vessels the vast majority of $A \beta$ co-localizes with ECM and not within SMC. A third limitation is that, similar to previous in vitro studies [71,72], the $A \beta 42$ concentrations used here are supraphysiological relative to the levels in human brain, CSF or cerebral interstitial fluid, which was required to be within the detection limits of our ELISA assay [73-75]. Future studies using more sensitive $A \beta$ assays that also use native neuronally-produced $\mathrm{A} \beta$ in bioengineered tissues would circumvent this limitation. Finally, the concentration of HDL used here is lower than in to normolipidomic individuals. HDL concentrations within plasma which roughly corresponds to $140 \mathrm{mg}$ apoA-I /dL [76]. We circulated $200 \mu \mathrm{g}$ protein/mL HDL in our experiments, similar to what 
has previously been published for other in vitro studies $[37,77]$, as we are limited by the availability of HDL, in particular HDL enriched in apoE.

\section{Conclusions}

In conclusion, we define multiple pathways by which HDL exhibits beneficial properties relevant to AD. HDL uses SR-BI to attenuate $A \beta$-mediated endothelial inflammation and employs multiple SR-BI-independent pathways to attenuate $A \beta$ deposition in engineered vessels. HDL reduces $A \beta 42$ uptake by SMC perhaps by reducing LRP1 levels, alters binding of $\mathrm{A} \beta 42$ to collagen-I likely by forming an HDL-A $\beta$ complex, and diminishes collagen-I production by SMC (Fig. 7). Intriguingly, these are influenced by the presence of apoE on HDL particles. All of these
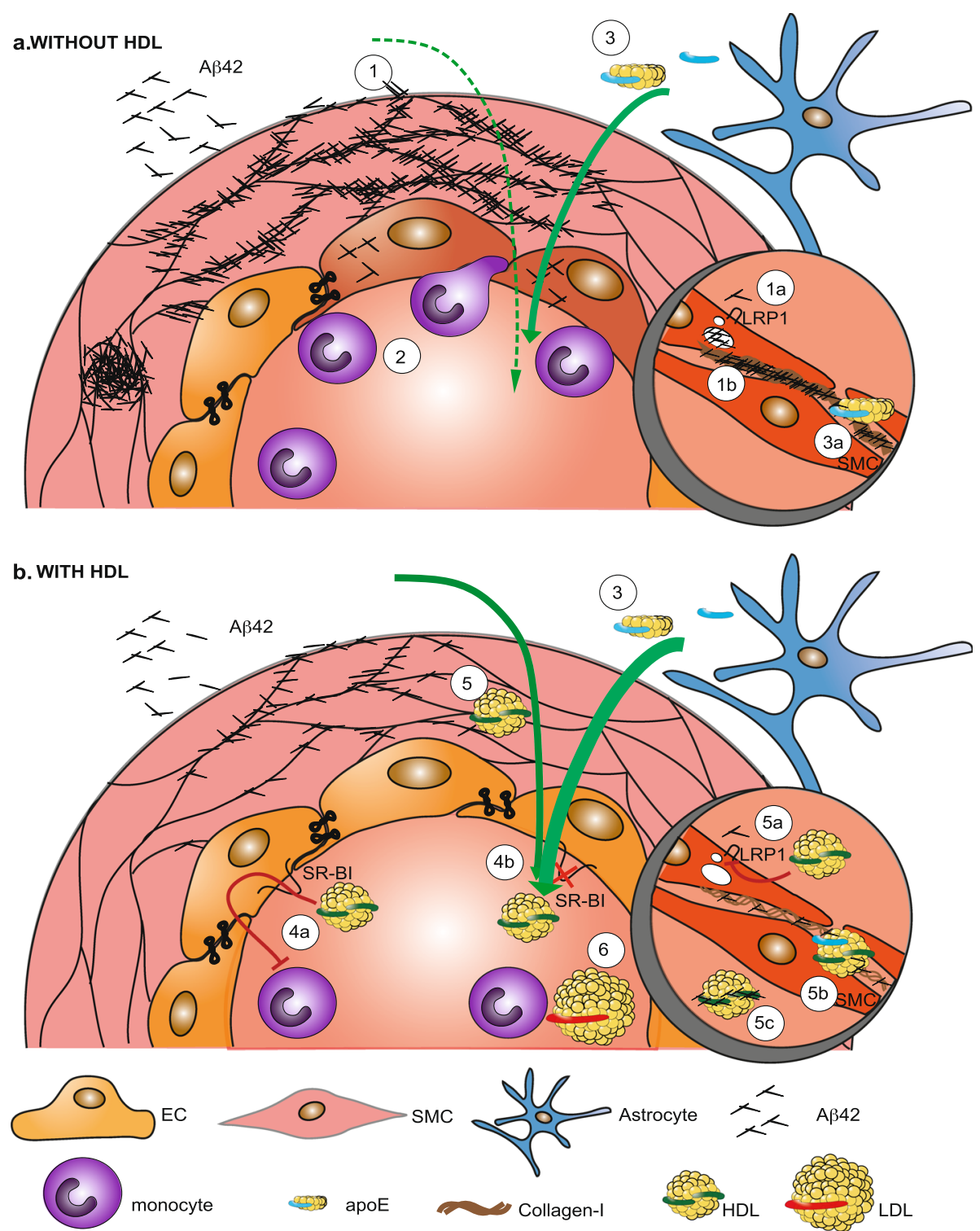

Fig. 7 Schematic of the mechanisms by which HDL is hypothesized to protect cerebrovascular functions in AD. a In the absence of HDL, when A $\beta$ peptides enter the vessel wall they are either taken up by SMC via LRP1 (1a) or become trapped in ECM, particularly when enriched in collagen-I (1) $\mathbf{1}$. 2) Accumulation of $A \beta$ in the vessel wall induces endothelial activation and subsequent binding and transmigration of bloodderived circulating monocytes. 3) Astrocytes on the antelumen of penetrating arteries secret apoE that reduces collagen-I levels in the vascular wall. $\mathbf{b}$ in the presence of HDL, 4) HDL reduces monocyte binding via SR-BI (4a), whereas reduction of CAA is independent of SR-BI (4b). 5) HDL enters the cerebrovascular wall through undefined mechanisms and reduce A $\beta$ uptake by SMC maybe by reducing LRP1 levels (5a), bind and remodel collagen-l fibres via $\mathrm{HDL}$-apoE particles $(\mathbf{5 b})$ and form a complex with $A \beta(\mathbf{5 c})$, all of which increase luminal recovery of $A \beta$. 6) The reduction of CAA is specific to $\mathrm{HDL}$ 
mechanisms promote $A \beta$ clearance through the vasculature, thereby reducing CAA. The findings in this study begin to elucidate an important mechanistic pathway concerning $\mathrm{AD}$ pathogenesis, identifies new potential therapeutic targets, and sheds new light on the role of peripherally-acting apoE in AD.

\section{Supplementary information}

Supplementary information accompanies this paper at https://doi.org/10. 1186/s13024-020-00366-8.

Additional file 1: Supplemental Figure 1. Schematic view of the bioengineered vessel and bioreactor. The left panel represents a schematic of the bioreactor design with the peristaltic pump, media container, circulation loop, and bioengineered vessel chamber. The bioengineered vessel separates the tissue chamber (brown) where $A \beta$ is injected from the circulation loop (red) where HDL is circulated. The right panel depict the schematic of bioengineered vessels composed of EC (yellow), SMC (orange) without (bipartite) or with (tripartite) astrocyte (blue). Non-woven PGA/PCL scaffold is showed in white and defines the number of SMC layers. Supplementary Figure 2. HDL and mix LDL delay $A \beta 42$ fibrillization. (a) A $\beta$ fibrillization was measured in a Thioflavin T cell-free assay over $7200 \mathrm{~min}$. (b) Maximal fluorescence, (c) time to halfmaximal fluorescence (V50) and (d) lag phases were calculated using Boltzmann curve analysis (vehicle $R^{2}=0.91 ; \mathrm{HDL} R^{2}=0.94$; $\mathrm{LDL} R^{2}=0.4$ ). Points in graphed data represent individual experiments, bars represent mean, error bars represent \pm SEM and data are presented as mean +/SEM and analysed by one way ANOVA ${ }^{*} P<0.05$, ${ }^{*} P<0.01,{ }^{* *} P<0.001$ and ${ }^{* * *} P<0.0001$. Supplementary Figure 3 . HDL does not reduce deposition of preformed $A \beta 42$ oligomers or fibrils in engineered tissues. (a) $1 \mu \mathrm{M} \mathrm{A} \beta 42$ was injected into the tissue chamber concomitantly with circulation of $200 \mu \mathrm{g} / \mathrm{mL} \mathrm{HDL}$ through the lumen before measuring $A \beta 42$ deposition in the GluHCl fraction by ELISA and examining Thioflavin S staining (white) after $24 \mathrm{~h}$ (* remaining scaffold). (b) A 342 oligomers were prepared by incubating monomers in RPMI for $48 \mathrm{~h}$ at $4^{\circ} \mathrm{C}$ before injection of $1 \mu \mathrm{M}$ oligomers into the tissue chamber while circulating $200 \mu \mathrm{g} /$ $\mathrm{mL} \mathrm{HDL}$ through the lumen. After $24 \mathrm{~h}, \mathrm{~A} \beta$ was measured in both RIPA and $\mathrm{GluHCl}$ fractions by ELISA. (c) A 342 fibrils were prepared by incubating monomers in RPMl for $48 \mathrm{~h}$ at $37^{\circ} \mathrm{C}$ before injection of $1 \mu \mathrm{M}$ fibres into the tissue chamber while circulating $200 \mu \mathrm{g} / \mathrm{mL} \mathrm{HDL}$ through the lumen. After $24 \mathrm{~h}, \mathrm{~A} \beta$ was measured in both RIPA and GluHCl fractions by ELISA. (d) $1 \mu \mathrm{M}$ A 42 monomers were injected into the antelumen $48 \mathrm{~h}$ before circulating $200 \mu \mathrm{g} / \mathrm{mL} \mathrm{HDL}$ through the lumen. After $24 \mathrm{~h}$, A 342 deposition was measured in RIPA and GluHCI fractions by ELISA. Thioflavin-S staining are representative image of 3 individual tissues. Points in graphed data represent individual bioengineered vessels, bars represent mean, error bars represent \pm SEM and analysed by Student's ttest. Supplementary Figure 4. HDL reduces FITC-A 342 uptake by EC and $\mathrm{HDL}$ does not increase $\mathrm{A} 342$ co-localization with lysosome in SMC. EC were grown in 2D monolayers for $2 \mathrm{~d}$ before treating with $1 \mu \mathrm{M}$ FITCA 342 without or with $200 \mu \mathrm{g} / \mathrm{mL} \mathrm{HDL}$ for $3 \mathrm{~h}$ (a) or $24 \mathrm{~h}$ (b) before dissociating cells and counting using flow cytometry. (c) SMC were grown in chamber slides for $2 \mathrm{~d}$ before treating with $5 \mu \mathrm{M}$ FITC-A 342 (depicted as yellow) without or with $200 \mu \mathrm{g} / \mathrm{mL} \mathrm{HDL}$. After $24 \mathrm{~h}$, SMC were fixed and stained for the lysosomal marker LAMP1 (magenta) before imaging using confocal microscopy. Points in graphed data represent individual bioengineered vessels, bars represent mean, error bars represent \pm SEM and analysed by Student's t-test ${ }^{*} P<0.05$ and ${ }^{* *} P<0.01$. Fluorescent images are representative of two separate experiments. Supplementary Figure 5. $\mathrm{HDL}$ does not alter $\mathrm{A} \beta 42$ entry from the circulation into the vascular wall. (a) $1 \mu \mathrm{M} \mathrm{A \beta 42} \mathrm{monomers} \mathrm{were} \mathrm{injecting} \mathrm{into} \mathrm{the} \mathrm{tissue}$ chamber with or without circulating $200 \mu \mathrm{g} / \mathrm{mL}$ of $\mathrm{HDL}$ through the lumen. After $24 \mathrm{~h}$ tissues were lysed in RIPA and RAGE levels were measured in bioengineered tissues using Western blot and normalized to GAPDH. $1 \mu \mathrm{M}$ AB42 monomers were injecting either into the tissue chamber or the circulation loop with or without circulating $200 \mu \mathrm{g} / \mathrm{mL}$ of $\mathrm{HDL}$ through the lumen. After $24 \mathrm{~h}, \mathrm{~A} \beta 42$ was measured in the tissue chamber (b), circulation (c), and tissue lysed in RIPA (d) by ELISA. (e) $1 \mu \mathrm{M}$
A 342 was injected into the tissue chamber with or without a blocking antibody against RAGE in the circulation. After $24 \mathrm{~h}$, tissues were lysed in RIPA A 342 levels were measured by ELISA. Points in graphed data represent individual bioengineered vessels, bars represent mean, error bars represent \pm SEM and analysed by Student's t-test or one-way ANOVA ${ }^{*} P<0.05$, ${ }^{*} P<0.01$, ${ }^{* *} P<0.001$ and ${ }^{*}{ }^{* *} P<0.0001$. Supplementary Figure 6. $A \beta$ deposition co-localizes with vascular ECM in post mortem human cortex. Human cortex (Brodmann area 9) were stained for $A \beta$ using 6 E10 (yellow) and collagen-IV (a), laminin (b), biglycan (c), HSP2 (d) and versican (e) (magenta). Expanded views of a vessel with CAA (1) and cortical A $\beta$ plaques (2) are shown on the right. Images are representative of four individual human donors. Supplementary Figure 7. A 342 forms a complex with HDL and reduces HDL's cholesterol efflux activity. (a) $1 \mu \mathrm{M}$ AB42 were incubated either with $200 \mu \mathrm{g} / \mathrm{mL}$ of HDL or BSA for $24 \mathrm{~h}$ at $37^{\circ} \mathrm{C}$ before gel-filtration chromatography separation. $\mathrm{HDL}$ alone (b) or A 442 monomers alone (c) were separated by gel-filtration chromatography and dot blotted fractions were probed against $A \beta(6 E 10)$ or $\mathrm{HDL}$ (apoA-II). Graphs and dot-blots show representative experiments from three individual FPLC runs. RAW 264.7 cells were loaded with $\mathrm{H}^{3}$-cholesterol and cholesterol efflux was measured in the presence of $H D L(\mathbf{d})$, lipid-free apoA-I (e) or no acceptor (f), pre-incubated with or without $1 \mu \mathrm{M} \mathrm{A} 342$ for $24 \mathrm{~h}$. Points in graphed data represent individual experiments, bars represent mean, error bars represent \pm SEM and analysed by Student's t-test ${ }^{*} P<0.05,{ }^{* *} P<0.001$ and ${ }^{* * *} P<0.0001$.

\section{Abbreviations}

AD: Alzheimer's disease; Apo : apolipoprotein; Aß: beta-amyloid;

CAA: cerebral amyloid angiopathy; CAD: coronary artery diseases;

EC: endothelial cells; ECM: extracellulat matrix; HDL: high-density lipoprotein; LDL: Iow-density lipoprotein; LRP1: Iow density lipoprotein receptor-related protein 1; RAGE: receptor for advanced glycation endproduct; RAP: receptorassociated protein; SMC: smooth-muscle cells

\section{Acknowledgements}

This work was supported by Weston Brain Institute Rapid Response grants awarded to JR (RR182093 \& RR150048), as well as Cure Alzheimer Fund, NSERC Discovery, and Canadian Consortium of Neurodegeneration and Aging (CCNA) grants to CLW. JR was further supported by Michael Smith Foundation for Health Research (MSFHR)/CCNA and UBC Faculty of Medicine Bluma Tischler fellowships. NRC was supported by grants from CIHR, Brain Canada, the Alberta Innovates Bio Solutions, the CCNA and the Giancarlo and Odette Tognetti Trust Foundation. EBB was supported by a UBC Four Year Doctoral Fellowship and a Canadian Institutes of Health Research Doctoral Fellowships. The Paul Heller Memorial Fund overseen by the Vancouver Foundation provided support for JMS.

\section{Authors' contributions}

$J R$ and CLW designed the research with input from JMS and LM. JR, EBB, EM, $Z G, M G, G B, A A$ and $A C$ performed the experiments and analyzed the data. $J R, C L W$ and NRC obtained the funding. JR and CLW drafted the manuscript and all authors reviewed and approved it.

\section{Availability of data and materials}

Raw data can be obtained from corresponding author.

\section{Ethics approval and consent to participate}

All experiments were conducted under an approved clinical protocol from the UBC Clinical Ethics Research Board after obtaining written informed consent from all subjects (H13-02719: isolation of vascular cells and H1403357: isolation of lipoproteins).

\section{Consent for publication}

Not applicable.

\section{Competing interests}

The authors declare that they have no competing interests.

\section{Author details}

${ }^{1}$ Department of Pathology and Laboratory Medicine, University of British Columbia, Vancouver, British Columbia V6T 1Z3, Canada. ${ }^{2}$ Djavad 
Mowafaghian Centre for Brain Health, University of British Columbia, Vancouver, British Columbia V6T 1Z3, Canada. ${ }^{3}$ Present address: Institute of Clinical Chemistry, University Hospital Zurich, 8000 Zurich, Switzerland. ${ }^{4}$ Department of Physics and Astronomy, University of British Columbia, Vancouver, British Columbia V6T 1Z1, Canada. ${ }^{5}$ Department of Neurology, University of British Columbia, Vancouver, British Columbia V6T 2B5, Canada. ${ }^{6}$ School of Biomedical Engineering, University of British Columbia, Vancouver, British Columbia V6T 1Z3, Canada. ${ }^{7}$ International Collaboration on Repair Discoveries, University of British Columbia, Vancouver, British Columbia V5Z 1M9, Canada.

\section{Received: 22 October 2019 Accepted: 13 February 2020 Published online: 25 March 2020}

\section{References}

1. Christina P. World Alzheimer's report 2018. Alzheimer's disease internations: world alzheimer report 2018; 2018. p. 1-48. https://doi.org/10.1111/j.00330124.1950.24_14.x

2. Selkoe DJ. Alzheimer disease and aducanumab: adjusting our approach. Nat Rev Neurol. 2019. https://doi.org/10.1038/s41582-019-0205-1.

3. Sevigny J, et al. The antibody aducanumab reduces $A \beta$ plaques in Alzheimer's disease. Nat Publ Group. 2016:537:50-6.

4. Howard R, Liu KY. Questions EMERGE as Biogen claims aducanumab turnaround. Nat Rev Neurol. 2019. https://doi.org/10.1038/s41582-019-0295-9.

5. Di Francesco JC, Longoni M, Piazza F. Anti-A $\beta$ autoantibodies in amyloid related imaging abnormalities (ARIA): candidate biomarker for immunotherapy in Alzheimer's disease and cerebral amyloid angiopathy. Front Neurol. 2015;6:4-6.

6. Laurin D, Masaki KH, White LR, Launer LJ. Ankle-to-brachial index and dementia: the Honolulu-Asia aging study. Circulation. 2007;116:2269-74.

7. Biffi A, Greenberg SM. Cerebral amyloid angiopathy: a systematic review. J Clin Neurol. 2011;7:1-9.

8. Nation DA, et al. Blood-brain barrier breakdown is an early biomarker of human cognitive dysfunction. Nat Med. 2019;25:270-6.

9. Bell RD, et al. Transport pathways for clearance of human Alzheimer's amyloid beta-peptide and apolipoproteins $E$ and $J$ in the mouse central nervous system. J Cereb Blood Flow Metab. 2007;27:909-18.

10. Sweeney MD, et al. Vascular dysfunction - the disregarded partner of Alzheimer's disease. Alzheimer's Dementia. 2019;15:158-67.

11. Santos CY, et al. Pathophysiologic relationship between Alzheimer's disease, cerebrovascular disease, and cardiovascular risk: a review and synthesis. Alzheimers Dement. 2017;7:69-87.

12. Vu THT, et al. Favorable cardiovascular health at young and middle ages and dementia in older age-the CHA study. J Am Heart Assoc. 2019;8: e009730.

13. Tan ECK, et al. Antihypertensive medication regimen intensity and incident dementia in an older population. J Am Med Dir Assoc. 2018;19:577-83.

14. Solomon A, Kivipelto M, Soininen H. Prevention of Alzheimer's disease: moving backward through the lifespan. Adv Alzheimers Dis. 2012;3:465-9.

15. Button EB, et al. HDL from an Alzheimer 's disease perspective. Curr Opin Lipidol. 2019;30:224-34.

16. Stukas S, Robert J, Wellington CL. High-density lipoproteins and cerebrovascular integrity in Alzheimer's disease. Cell Metab. 2014;19:574-91.

17. Mineo C, Shaul PW. Novel biological functions of high-density lipoprotein cholesterol. Circ Res. 2012:111:1079-90.

18. Sacre SM, Stannard AK, Owen JS. Apolipoprotein E (apoE) isoforms differentially induce nitric oxide production in endothelial cells. FEBS Lett. 2003:540:181-7.

19. Zuliani $\mathrm{G}$, et al. Relationship between low levels of high-density lipoprotein cholesterol and dementia in the elderly. The InChianti study. J Gerontol A Biol Sci Med Sci. 2010;65:559-64.

20. Merched A, Xia Y, Visvikis S, Serot JM, Siest G. Decreased high-density lipoprotein cholesterol and serum apolipoprotein Al concentrations are highly correlated with the severity of Alzheimer's disease. Neurobiol Aging. 2000;21:27-30

21. Reitz C, et al. Association of higher levels of high-density lipoprotein cholesterol in elderly individuals and lower risk of late-onset Alzheimer disease. Arch Neurol. 2010:67:1491-7.

22. Lefterov I, et al. Apolipoprotein A-I deficiency increases cerebral amyloid angiopathy and cognitive deficits in APP/PS1DeltaE9 mice. J Biol Chem. 2010;285:36945-57.
23. Button EB, et al. ApoA-I deficiency increases cortical amyloid deposition, cerebral amyloid angiopathy, cortical and hippocampal astrogliosis, and amyloid-associated astrocyte reactivity in APP/PS1 mice. Alzheimers Res Ther. 2019;11:1-18.

24. Fagan AM, et al. ApoAl deficiency results in marked reductions in plasma cholesterol but no alterations in amyloid- $\beta$ pathology in a mouse model of Alzheimer's disease-like cerebral amyloidosis. Am J Pathol. 2004;165:1413-22.

25. Contu L, Carare RO, Hawkes CA. Knockout of apolipoprotein A-I decreases parenchymal and vascular $\beta$ - amyloid pathology in the Tg2576 mouse model of Alzheimer's disease. Neuropathol Appl Neurobiol. 2019:1. https:// doi.org/10.1111/nan.12556.

26. Lewis $\mathrm{TL}$, et al. Overexpression of human apolipoprotein A-I preserves cognitive function and attenuates neuroinflammation and cerebral amyloid angiopathy in a mouse model of Alzheimer disease. J Biol Chem. 2010;285: 36958-68.

27. Robert J, et al. Reconstituted high-density lipoproteins acutely reduce soluble brain A levels in symptomatic APP/PS1 mice. Biochim Biophys Acta. 2015;1862:1027-36.

28. Fernández-de Retana $\mathrm{S}$, et al. Intravenous treatment with human recombinant ApoA-I Milano reduces beta amyloid cerebral deposition in the APP23-transgenic mouse model of Alzheimer's disease. Neurobiol Aging. 2017;60:116-28.

29. Gordon SM, et al. A comparison of the mouse and human lipoproteome: suitability of the mouse model for studies of human lipoproteins. J Proteome Res. 2015;14:2686-95.

30. Getz GS, Reardon CA. Animal models of atherosclerosis. Arterioscler Thromb Vasc Biol. 2012:32:1104-15.

31. Robert J, et al. Clearance of beta-amyloid is facilitated by apolipoprotein $E$ and circulating high-density lipoproteins in bioengineered human vessels. eLife. 2017;6:e29595.

32. Robert J, et al. High-density lipoproteins suppress Aß-induced PBMC adhesion to human endothelial cells in bioengineered vessels and in monoculture. Mol Neurodegener. 2017;12:60.

33. Weisgraber KH, Mahley RW. Subfractionation of human high density lipoproteins by heparin-Sepharose affinity chromatography. J Lipid Res. 1980;21:316-25

34. Zhao N, Liu C-C, Qiao W, Bu G. Apolipoprotein E, receptors, and modulation of Alzheimer's disease. Biol Psychiatry. 2018;83:347-57.

35. Robert J, et al. Interleukin 6 stimulates endothelial binding and transport of high-density lipoprotein through induction of endothelial lipase. Arterioscler Thromb Vasc Biol. 2013;33:2699-706.

36. Morton AM, Furtado JD, Mendivil CO, Sacks FM. Dietary unsaturated fat increases HDL metabolic pathways involving apoE favorable to reverse cholesterol transport. JCI Insight. 2019;4:1-14.

37. Robert J, et al. A three-dimensional engineered artery model for in vitro atherosclerosis research. PLoS One. 2013:8:e79821.

38. Fan J, et al. Small molecule inducers of ABCA1 and apoE that act through indirect activation of the LXR pathway. J Lipid Res. 2018;59:830-42.

39. Cox D, Selig E, Griffin MDW, Carver JA, Ecroyd H. Small heat-shock proteins prevent a-synuclein aggregation via transient interactions and their efficacy is affected by the rate of aggregation. J Biol Chem. 2016;291:22618-29.

40. Attems J, Jellinger KA. The overlap between vascular disease and Alzheimer's disease--lessons from pathology. BMC Med. 2014;12:206.

41. McGowan E, et al. Abeta42 is essential for parenchymal and vascular amyloid deposition in mice. Neuron. 2005;47:191-9.

42. Rohrer L, et al. High-density lipoprotein transport through aortic endothelial cells involves scavenger receptor BI and ATP-binding cassette transporter G1. Circ Res. 2009;104:1142-50.

43. Koldamova RP, Lefterov IM, Lefterova MI, Lazo JS. Apolipoprotein A-I directly interacts with amyloid precursor protein and inhibits a beta aggregation and toxicity. Biochemistry. 2001;40:3553-60.

44. Shih Y-H, et al. Apolipoprotein C-III is an amyloid- $\beta$-binding protein and an early marker for alzheimer's disease. J Alzheimers Dis. 2014:1-11. https://doi. org/10.3233/JAD-140111.

45. Manousopoulou A, et al. Systems proteomic analysis reveals that clusterin and tissue inhibitor of metalloproteinases 3 increase in leptomeningeal arteries affected by cerebral amyloid angiopathy. Neuropathol Appl Neurobiol. 2017;43:492-504.

46. Camacho J, et al. Brain ApoA-I, ApoJ and ApoE immunodetection in cerebral amyloid angiopathy. Front Neurol. 2019;10:1-12. 
47. Stukas $S$, et al. Intravenously injected human apolipoprotein A-I rapidly enters the central nervous system via the choroid plexus. J Am Heart Assoc. 2014;3:e001156.

48. Kanekiyo T, Liu CC, Shinohara M, Li J, Bu G. LRP1 in brain vascular smooth muscle cells mediates local clearance of Alzheimer's amyloid-beta. J Neurosci. 2012;32:16458-65.

49. Deane $R$, et al. RAGE mediates amyloid-beta peptide transport across the blood-brain barrier and accumulation in brain. Nat Med. 2003;9:907-13.

50. Burwinkel M, Lutzenberger M, Heppner FL, Schulz-Schaeffer W, Baier M. Intravenous injection of beta-amyloid seeds promotes cerebral amyloid angiopathy (CAA). Acta Neuropathol Commun. 2018;6:23.

51. Naish D, et al. Peripherally applied Ab-containing inoculates induce cerebral b-amyloidosis. Science (New York, NY). 2009;227:422-7.

52. Kothapalli D, et al. Cardiovascular protection by ApoE and ApoE-HDL linked to suppression of ECM gene expression and arterial stiffening. Cell Rep. 2012;2:1259-71.

53. Brodsky BB, Persikov AV. Molecular structure of the collagen triple helix. Adv Protein Chem. 2005;70:301-39.

54. Linton MF, et al. Phenotypes of apolipoprotein B and apolipoprotein E after liver transplantation. J Clin Invest. 1991;88:270-81.

55. Thanopoulou K, Fragkouli A, Stylianopoulou F, Georgopoulos S. Scavenger receptor class B type I (SR-BI) regulates perivascular macrophages and modifies amyloid pathology in an Alzheimer mouse model. Proc Natl Acad Sci U S A. 2010;107:20816-21

56. Ruzali WAW, Kehoe PG, Love S. Influence of LRP-1 and apolipoprotein E on amyloid- $\beta$ uptake and toxicity to cerebrovascular smooth muscle cells. J Alzheimers Dis. 2013;33:95-110.

57. Bell RD, et al. SRF and myocardin regulate LRP-mediated amyloid-beta clearance in brain vascular cells. Nat Cell Biol. 2009;11:143-53.

58. Lawson $\mathrm{JH}$, et al. Bioengineered human acellular vessels for dialysis access in patients with end-stage renal disease: two phase 2 single-arm trials. Lancet. 2016:387:2026-34.

59. Richiardi J, et al. Altered cerebrovascular reactivity velocity in mild cognitive impairment and Alzheimer's disease. Neurobiol Aging. 2015;36:33-41.

60. Rasmussen KL, Tybjærg-Hansen A, Nordestgaard BG, Frikke-Schmidt R. Plasma apolipoprotein E levels and risk of dementia-a Mendelian randomization study of 106,562 individuals. Alzheimers Dement. 2017;14:71-80.

61. Rasmussen KL, Tybjærg-Hansen A, Nordestgaard BG, Frikke-Schmidt R. Absolute 10-year risk of dementia by age, sex and APOE genotype: a population-based cohort study. Can Med Assoc J. 2018;190:E1033-41.

62. Rasmussen $\mathrm{KL}$, Tybjærg-Hansen A, Nordestgaard BG, Frikke-Schmidt R. Plasma levels of apolipoprotein $\mathrm{E}$ and risk of dementia in the general population. Ann Neurol. 2015;77:301-11.

63. Hawkes CA, et al. Disruption of arterial perivascular drainage of amyloidbeta from the brains of mice expressing the human APOE epsilon4 allele. PLoS One. 2012;7:e41636.

64. Salloway S, et al. Effect of APOE genotype on microvascular basement membrane in Alzheimer' 's disease. J Neurol Sci. 2002;204:183-7.

65. Hultman K, Strickland S, Norris EH. The APOE $\varepsilon 4 / \varepsilon 4$ genotype potentiates vascular fibrin(ogen) deposition in amyloid-laden vessels in the brains of Alzheimer's disease patients. J Cereb Blood Flow Metab. 2013;33:1251-8.

66. Wilson LM, et al. High density lipoproteins bind Abeta and apolipoprotein C-II amyloid fibrils. J Lipid Res. 2006:47:755-60.

67. Qi Y, et al. Apolipoprotein E-containing high-density lipoprotein (HDL) modifies the impact of cholesterol-overloaded HDL on incident coronary heart disease risk: a community-based cohort study. J Clin Lipidol. 2018;12: 89-98.e2.

68. Wu C-C, et al. Human umbilical vein endothelial cells protect against hypoxic-ischemic damage in neonatal brain via stromal cell-derived factor 1/C-X-C chemokine receptor type 4. Stroke. 2013;44:1402-9.

69. Akiyama $\mathrm{H}$, et al. Blood-brain barrier formation of grafted human umbilical vein endothelial cells in athymic mouse brain. Brain Res. 2000;858:172-6.

70. Keable A, et al. Deposition of amyloid $\beta$ in the walls of human leptomeningeal arteries in relation to perivascular drainage pathways in cerebral amyloid angiopathy. Biochim Biophys Acta. 2016;1862:1037-46.

71. Takamatsu K, et al. Degradation of amyloid beta by human induced pluripotent stem cell-derived macrophages expressing Neprilysin-2. Stem Cell Res. 2014;13:442-53.

72. $\quad X u X$, et al. Prevention of $\beta$-amyloid induced toxicity in human iPS cellderived neurons by inhibition of Cyclin-dependent kinases and associated cell cycle events. Stem Cell Res. 2013;10:213-27.
73. Brody DL, et al. Amyloid-beta dynamics correlate with neurological status in the injured human brain. Science (New York, NY). 2008;321:1221-4.

74. Seubert $P$, et al. Isolation and quantification of soluble Alzheimer's $\beta$ peptide from biological fluids. Nature. 1992;359:325-7.

75. Herukka S-K, et al. Amyloid- $\beta$ and tau dynamics in human brain interstitial fluid in patients with suspected Normal pressure hydrocephalus. J Alzheimers Dis. 2015;46:261-9.

76. Koren E, Puchois P, McConathy WJ, Fesmire JD, Alaupovic P. Quantitative determination of human plasma apolipoprotein A-I by a noncompetitive enzyme-linked immunosorbent assay. Clin Chim Acta. 1985;147:85-95.

77. Datta $G$, et al. Effects of increasing hydrophobicity on the physical-chemical and biological properties of a class a amphipathic helical peptide. J Lipid Res. 2001;42:1096-104.

\section{Publisher's Note}

Springer Nature remains neutral with regard to jurisdictional claims in published maps and institutional affiliations.

\section{Ready to submit your research? Choose BMC and benefit from:}

- fast, convenient online submission

- thorough peer review by experienced researchers in your field

- rapid publication on acceptance

- support for research data, including large and complex data types

- gold Open Access which fosters wider collaboration and increased citations

- maximum visibility for your research: over $100 \mathrm{M}$ website views per year

At BMC, research is always in progress.

Learn more biomedcentral.com/submissions 